\title{
SUPPORTING GIRLS TOWARDS THE DEVELOPMENT OF POSITIVE MATHEMATICAL IDENTITY
}

\author{
AS A dissertation submitted to the faculty of \\ 35 \\ 2019 \\ EDD \\ .$R 49$ \\ San Francisco State University \\ In partial fulfillment of \\ the requirements for \\ the Degree
}

Doctor of Education

In

Educational Leadership

by

Mary Jennifer Reynolds

San Francisco, California

May 2019 
Copyright by

Mary Jennifer Reynolds

2019 


\section{CERTIFICATION OF APPROVAL}

I certify that I have read Supporting Girls Towards the Development of Positive Mathematical Identity by Mary Jennifer Reynolds, and that in my opinion this work meets the criteria for approving a thesis submitted in partial fulfillment of the requirement for the degree Doctor of Education in Educational Leadership at San Francisco State University.

S Susk Hilton

Stephanie Sisk-Hilton, Ph.D.

Professor, Elementary Education

San Francisco State University

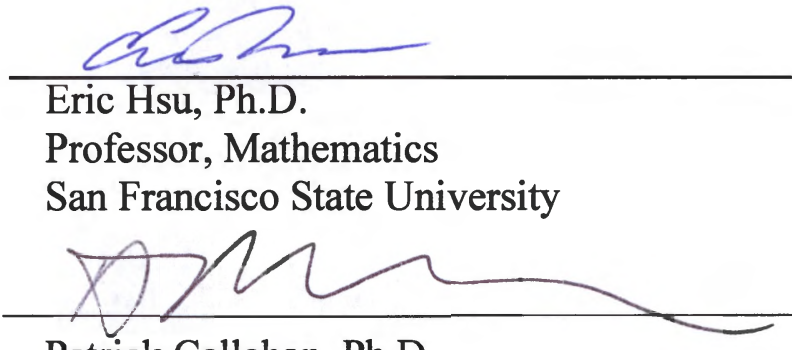

Patrick Callahan, Ph.D.

$\mathrm{CEO} /$ Founder

Callahan Consulting, Inc. 


\title{
SUPPORTING GIRLS TOWARDS THE DEVELOPMENT OF POSITIVE MATHEMATICAL IDENTITY
}

\author{
Mary Jennifer Reynolds \\ San Francisco, California \\ 2019
}

The purpose of this dissertation was to further support female students success in mathematics as it related to the classroom and beyond. The study documented girls' experiences and feelings about math learning and contextualized their responses by comparing them to those of their male classmates. This study provided insights to what educators can do, specifically, to support female students' success in mathematics. Current research provides valuable information about how to increase opportunities for female students to engage in meaningful opportunities for learning and discourse. This study adds to existing research by documenting female students' perspectives on how they experience the mathematics classroom. This study discussed how female students interpret supporting and challenging pedagogical structures that they have experienced and currently experience.

I certify that the abstract is a correct representation of the content of this dissertation.

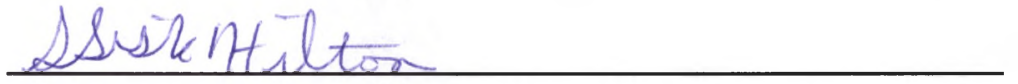

Chair, Dissertation Committee

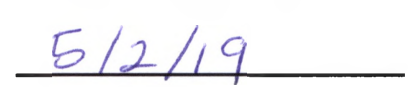

Date 


\section{ACKNOWLEDGEMENTS}

This work is dedicated to my daughter, Camille Reynolds-Briggs. I hope you will always love math. You can change the world.

I would like to acknowledge my mom and dad, Richard and Cynthia, for their support.

To Betha MacClain, my critical colleague and friend, thank you for reminding me to slow down. Thank you for being there for me.

To Dr. Gary Bates your constant feedback and kindness is without limits.

To my dance moms - Jessie, April, Aaryn, and Margaret, your kindness, compassion, and friendship, and support helped me through all the way to the finish line and a "Platinum" award!

To my committee- Dr. Stephanie Sisk-Hilton, Dr. Eric Hsu, and Dr. Patrick Callahan, your support and guidance made all the difference.

Thank you to the children who participated in this research.

Last but not least, to Jabar Banks- rest in power. 


\section{TABLE OF CONTENTS}

List of Table viii

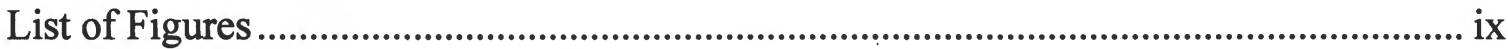

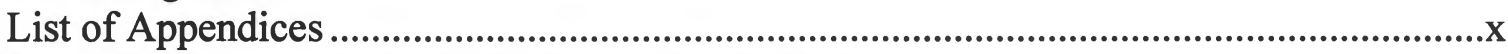

Chapter One: Introduction to Problem and Study...................................................................

Problem with Girls' Mathematics Instruction .............................................................

Female Students' Achievement Gap in Mathematics................................................3

Purpose of the Study .....................................................................................................5

Conceptual Framework ....................................................................................................7

Attitudes, Discourses and Mindsets..........................................10

Significance of the Study ........................................................................................11 Increase Understanding of How Female Students Develop Positive

Attitudes Increase Leaders' Abilities to Support Female Students' Mathematics

Learning

Chapter Two: Literature Review …………………….....................................................15

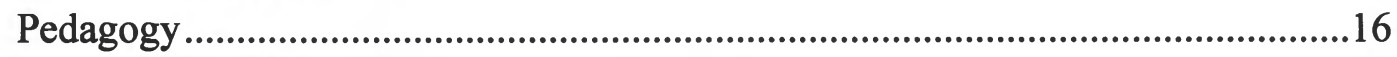

Procedural and Conceptual Pedagogy ............................................................18

Discourse as a Support for Complex Teaching.............................................19

Social Justice and Culturally Relevant Pedagogy ........................................21

Teacher Mindset............................................................................................25

Student Mindset ..........................................................................................28

Mathematical Identity .....................................................................................31

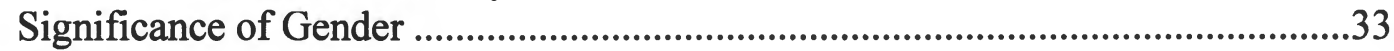

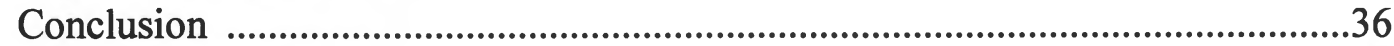

Chapter Three: Methodology ................................................................................................38

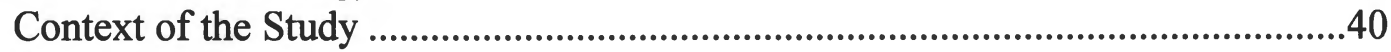

Research Question.........................................................42

Role of the Researcher..................................................42

Research Design....................................................................................................43

Participant Selection ...................................................................................................44

Ethics and Protection of Human Subjects................................................................46

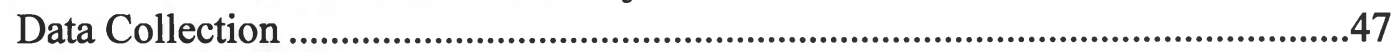

Students' Responses to Written Prompts .....................................................48

Focus Group Interviews ..............................................................................48

Individual Interviews ...................................................................................49

Classroom Observations of Focus Students................................................50

Formal Mathematics Assessment Data.................................50

Data Analysis.............................................................52

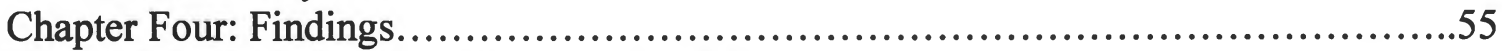

Analysis of Written Prompts - Female ......................................55

Male Student Responses.................................................58

Analysis of Focus Group Interviews.......................................59

Focus Group One: Attitudes Towards Math...........................59 
Focus Group Two: Discussion of Math Teaching Video.........................67

Analysis of Video for Gender Differences.....................................70

Individual Interviews Analysis...................................................71

Formal Mathematics Assessment Data.........................................75

Observations of Focal Students and Case Study ................................78

Student Perceptions of Classroom Management...................................79

Understanding Students' Hope and Confidence..........................81

The Role of Gender as Described by Focal Students.....................83

Summary and Synthesis.................................................. 84

Chapter Five: Discussion and Recommendations...................................85

Key Findings........................................................... 85

Evidence in Relation to Research Question..................................8

Relationship of Findings to Existing Literature ...............................89

Limitations of the Research.............................................92

Implications for Practice....................................................994

Recommendations for Classroom Instruction................................99

Recommendations for School Leadership.....................................95

Recommendations for Budget and Policy ...................................96

Recommendations for Future Research.....................................99

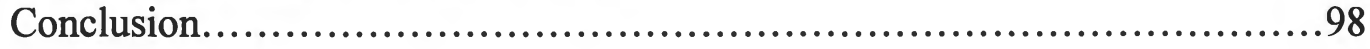




\section{LIST OF TABLES}

Table

1. Data collection information...................................................................51

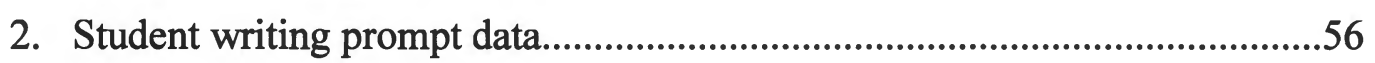

3. Focus group response themes by gender .........................................................61

4. Focus group interviews: Conversation response types......................................67

5. Focus group with video: Participant response codes by gender........................69

6. Individual interviews: Participant response codes by gender.................72

7. Female student achievement data...........................................77

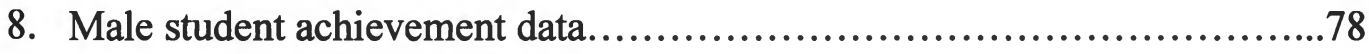




\section{LIST OF FIGURES}

Figures

Page

1. Math interconnections across discourses and mindsets.....................................10

2. Math interconnections across discourses and mindsets....................................42 


\section{LIST OF APPENDICES}

Appendix Page

1. Parental permission letter ...................................................................................100

2. Writing prompt and interview questions........................................................104

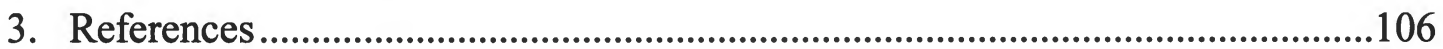




\section{Chapter One: Introduction to Problem and Study}

"Mathematics is the purest of the arts, as well as the most misunderstood."

\section{-A Mathematician's Lament}

2019 is a critical time in which educators need to take stock of mathematical

discourse and its impact on female students' attitudes towards mathematics in elementary classrooms. California adopted the Common Core standards in 2013, and six years later, the standards are still being implemented. In the interim, mathematical achievement has been stagnant. The state needs to decide to change course or stay the course. What fifth grade female students have to say about mathematics can add valuable insights to this topic.

In addition, fifth grade is a critical time to take stock of how students have experienced mathematics and how it is affecting their performance. By the fifth-grade students have experienced different types of teaching methods, both in the classroom and in the world (Bachman, 2015). Fifth grade students are (a) on the brink of a mathematical transition from the K-5th grade standards progressions to the 6th-8th grade standards progressions, and (b) on the verge of transitioning from elementary school to middle school.

\section{Problem with Girls' Mathematics Instruction}

By the time they have reached the fifth grade, students have experienced 
traditional teaching methods. In some schools, traditional teaching methods include learning opportunities that look like children completing worksheets, answering written questions, and doing seat work (Delpit, 2012). Traditional teaching methods such as "sit and get," lecture, rote memorization, worksheets, recall speed activities, and one-shot grading do nothing more than contribute to an ever-widening achievement gap and do not support student discourse (Delpit, 2012). Unfortunately, this is all too common an experience. Student learning experiences related to traditional teaching methods have been summarized over time in U.S. history as highly typical (Goodlad, 1984; Delpit, 2012). Although mathematics education researchers have identified and studied more effective ways of teaching, particularly focusing on engagement in discourse and other core mathematical practices, these approaches are still far from the norm in elementary mathematics classrooms (Delpit, 2012).

Possibly, by the time students have reached fifth grade they may also have experienced engaging learning opportunities. In schools where a diverse population of children perform at high levels, teachers actively engage students in meaningful discourse opportunities such as having students explain concepts to their peers and ask questions that require deep thought (Delpit, 2012). Engaging learning opportunities are congruent to positive student learning experiences that build agency and confidence. However, engaging forms of mathematical learning are rarer in low performing schools. 
As a result, around the fifth grade the racial achievement gap in mathematics becomes pronounced (Bachman, 2015). The 2017 CAASPP (California Assessment of Student Performance and Progress) demonstrates how white students have higher scores. The results show that while $62 \%$ of white students in the fourth grade met or exceeded standards, only $34 \%$ of Hispanic or Latino students met or exceeded standards, and just $28 \%$ of Black or African American students met or exceeded standards (California Department of Education, 2018). Over time, the gap between the performance of white and Asian students has increased, while the performance of Hispanic and Black students has stagnated or decreased (Bachman, 2015).

\section{Female Students' Achievement Gap in Mathematics}

While female students begin at an equal achievement level with male students at the onset of their educational pathway in mathematics, a gap quickly appears in fourth and fifth grades. By the time female and male students are in high school, the achievement level continues to favor male students through the duration of high school (National Center for Education Statistics, 2018). Achievement differences are magnified in more rigorous assessments of mathematics achievement such as PISA and NAEP.

PISA is an international test administered to 15 -year-old students. The 2015 PISA scores for the United States show a nine-point difference in favor of male students. The 2012 PISA scores for the United States show a five-point difference of average 
scores in favor of male students. The gender score gap is increasing over time.

Additionally, the National Assessment of Educational Progress (NAEP) results show a statistically significant score gap between male and female students that has existed and remained constant over the past decade (National Center for Education Statistics, 2018). CAASPP data shows a small, but steady increase of male students outperforming female students (California Department of Education, 2018). This performance gap begins in fifth grade. The male-female math gap is even larger for female students of color. Math scores for female students of color have decreased over time.

2017 NAEP results show sixty-two percent of Hispanic and Black fourth-grade female students scored "Basic" or "Below Basic." These results were two percentage points lower compared to 2015, the previous assessment year (National Center for Education Statistics, 2018). The trend in fourth-grade NAEP mathematics average scores for female Hispanic students who qualify for free and reduced lunch is that their scores have remained well-below the proficient mark of 250 with a score of 224 . The overall score for Hispanic female students dropped from a score of 230 to 229 between the testing years of 2015 and 2017. From 2005 to 2017, the scores of female Hispanic students have flatlined. In other words, their scores have more or less stayed the same ranging from 226-229, and are still well-below the proficient mark of 250. From 2005 to 
2017, white and Asian male students' scores have remained at or above proficient ranging from 246-258.

PISA, NAEP and CAASPP scores show the progress of female students as a negative trend in mathematics scores over time. International, district, and state data confirm that the mathematics achievement gap is increasing. The achievement gap is focused on students who are female, socio-economically disadvantaged, English learners, and students from racial groups underrepresented in higher levels of education. Data shows that within the scope of K-12 mathematics education, there are complex issues of achievement disparity, explicit and implicit racism, and sexism (National Center for Education Statistics, 2018). Given that fifth grade is also a critical point in the development of girls' attitudes towards mathematics, the longitudinal data adds to the evidence of an achievement gap that includes race, gender and socio-economic status. Maybe it is time for the state to decide what to do based on what the students have to say. Student voice can add insights as to how they learn and experience math, both in the classroom and the real world.

\section{Purpose of the Study}

The purpose of this study is to further examine and investigate the role of mathematical discourse in elementary classrooms, more specifically, how discourse can support the achievement and progress of female students. Discourse has a direct link to learning mathematics. Students who read, write, and speak about their mathematical 
learning can then internalize their learning. When something is known, it becomes a part of the individual's narrative. This study will also examine the relationship between mathematical discourse and mathematical attitudes.

To further support the reason to investigate female mathematical attitudes, possible causes of gender difference in performance have been examined by Steele (1997, 2012), who looked at the performance of men and women on a mathematics test through the lens of stereotype threat. A stereotype threat is, "the experience of anxiety or concern in a situation where a person has the potential to confirm a negative stereotype about the social group to which they belong" (Delpit, 2012, p.17). According to Steele (1997), "As for the woman who spends considerable time in a competitive, male-oriented math environment, it can pressure disidentification, a reconceptualization of the self and of one's values so as to remove the domain as a self-identity, as a basis of selfevaluation." This impacts female attitudes towards mathematics.

When students can explain what they have learned to others, they have demonstrated an internalization of knowledge. The next logical step with this rationale is that learning should lead to increased achievement and increased confidence, as well as positive attitudes in mathematics. When the stereotype threat is decreased or eliminated, confidence and achievement as it relates to attitude increases.

The research question for this study is, "How do instructional practices that fifth 
grade female students experience at school support and relate to the development of positive mathematical attitudes?"

\section{Conceptual Framework}

This study is built on the intersectionality of mathematical discourse, learning, and mathematical attitudes. Critical discourse theorist, Gee (2004) defines discourse as distinctive ways people talk, read, write, think, believe, value, act, and interact with things and other people to get recognized (and recognize themselves) as a distinctive group or distinctive kinds of people. The term, mathematical discourse, is defined by Banse, Palacios, Merritt, and Rimm-Kaufman, (2016) as student communication of mathematical ideas with teachers and peers. A combination of both definitions suggests that students communicate their mathematical ideas to their teachers and peers via talking, writing, actions, and interactions.

Educational theorist, Sarason (2004) explained learning as a social activity that has a normative aspect. A normative aspect comes from the idea that students follow the classroom norms, which can vary between classrooms. For example, one classroom may be focused on collaborative participatory group work that builds conceptual understandings, whereas another classroom may place value and focus on individual seat work grounded in basic skills and procedures. These normative aspects shape the student's experience with mathematics. 
Gee (2004) defines learning as a type of social interaction in which knowledge is distributed across people and their tools and technologies, dispersed at various sites, and stored in links among people, their minds and bodies, and specific affinity groups. An inference can be made that learning has taken place when the learner can speak coherently and concisely about what she has learned. The relationship between learning and discourse is a complex one, and given the definitions of each, a possible conclusion is that discourse is needed for learning to take place. It is apparent that discourse is inextricably tied to identity, and that identity is shaped as positive or negative in relationship to math. Identity shapes attitudes towards math as either positive, negative, or neutral.

Teachers can learn about their practice through interactions with their students. Sarason (2004) further explained the idea of learning when he described the term bidirectional learning as an idea in which learning takes place when the teacher learns from the student and the student learns from the teacher. Bidirectional learning is a continuous process that supports discourse because the active parts of discourse- writing, talking, acting, and interacting, take place in the following ways: student to student, teacher to student, and student to teacher. Learning is a social activity that is dependent on interactions with students' individual ideas and their interactions with others.

The idea of discourse in the classroom is defined in terms of who is talking, 
writing, and interacting with the math and how that supports student learning. Based on Gee (2004) and Sarason's (2004) theories of learning and discourse, learning is a social interaction where students build critical consciousness by problematizing the conditions in which they live through active communication with peers and their teachers.

My understanding of the complexity of math learning and how it relates to discourse is demonstrated by the conceptual theory depicted in Figure 1. The conceptual theory is one in which female mathematical discourse is developed by the learning opportunities that support and link social discourse to academic discourse. Female mathematical discourse corresponds to teacher mindset and student mindset. What students think about themselves in terms of their mathematical identity and what teachers think about students' abilities impacts learning, as well as students' attitudes towards math. Teacher mindset is indirectly related to academic and social discourse because the teacher is actively bridging the two to support the student. The teacher plays an important and influential role in learning. 


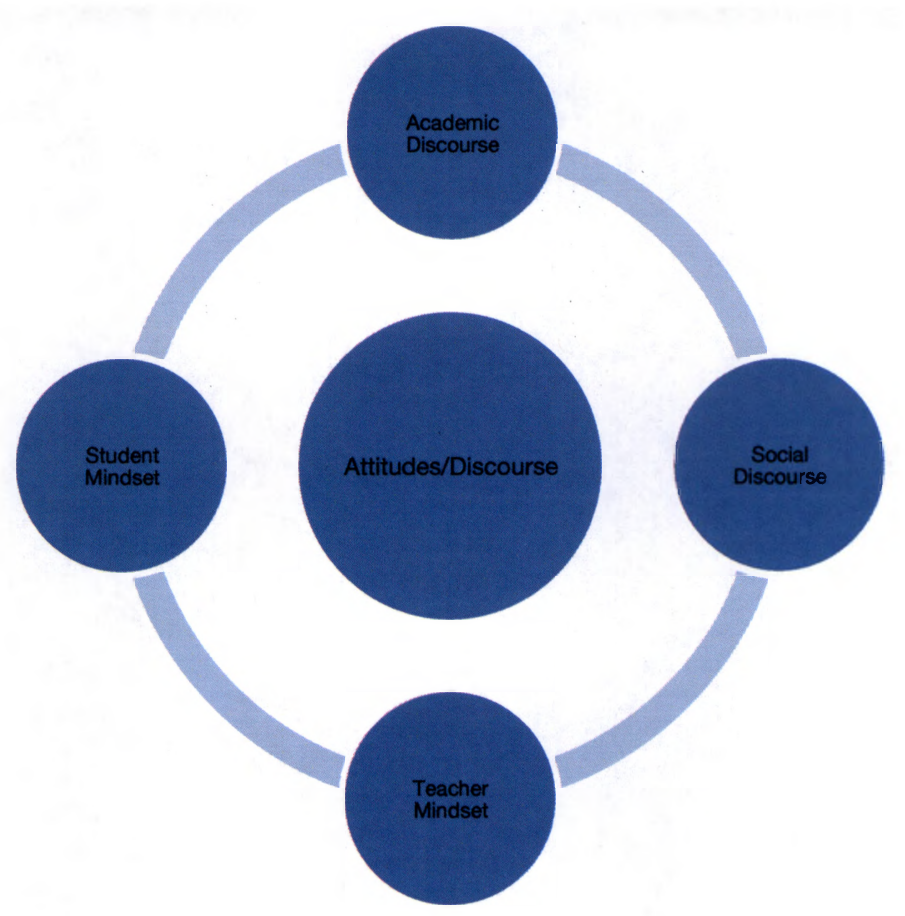

Figure 1. Math interconnections across discourses and mindsets.

\section{Attitudes, Discourses and Mindsets}

The central idea of the conceptual theory is that mathematical discourse and attitude are defined as the ways students and teachers act towards mathematics. Much of the way they do this is influenced by their mindsets either being positive or negative. The social discourse versus the academic discourse shows up in the ways we talk about math. The ways in which the circles overlap represents their interconnectedness. The paths between the circles reinforces the overlap and connections between discourse and attitudes. Both students and teachers bring positive and negative mindsets to math and those mindsets are a part of their mathematical discourse that shape their mathematical identity and attitudes towards mathematics. Students' attitudes towards mathematics 
corresponds to their achievement and confidence.

\section{Significance of the Study}

This study is significant because it will further the work that needs to be done to support teachers with instructional practices with discourse opportunities unique to female students. Additionally, the study includes something that is glaringly and often missing from the conversation, especially in elementary education- student voice. Author Delpit (2012) explained that good teaching consists of, "They [teachers] ask students to explain concepts to their peers. They ask questions that require deep thought, and they demand responses" (p. 42). Adding the ideas that students have about teaching and learning math is both important and insightful.

\section{Increase Understanding of How Female Students Develop Positive Attitudes}

Socio-economically disadvantaged students, Latinx students, African American students, and female students are marginalized groups who are present in mathematics classrooms, yet their math achievement lags behind. This is an issue of equity and social justice because all students deserve an equitable learning experience to position themselves as successful doers of math. Researcher, Nasir (2016) provided the following commentary for why educators should care about race, culture, and gender as it pertains

to mathematics, "High-quality mathematics instruction disrupts unequal access to mathematics learning for students from marginalized groups" (p.7). Nasir goes on to point out that when educators see teaching mathematics as an opportunity to disrupt 
stereotypes such as "girls can't do math," great change can take place. Student voices as they relate to their mathematical experiences can disrupt gender stereotypes as well.

The overall value of this study is that it proves the need for further research to be done to find out what female students think are the best ways they learn and develop positive attitudes towards mathematics. Increased opportunities for meaningful mathematical discourse in mathematics classrooms can improve student learning outcomes.

\section{Increase Leaders' Abilities to Support Female Students' Mathematics Learning}

The relationship between discourse and leadership creates a solution to increase opportunities for female students to engage in mathematical discourse. Specifically, teachers and other school leaders can learn from what female students have to say about how they learn math, and how that shapes their attitudes towards math. Culturally Responsive School Leadership (CRSL) can provide space for specific types of mindset and pedagogical shifts to increase discourse, and positive learning experiences for female students to be able to position themselves as successful doers of mathematics. Khalifa, Gooden, and Davis's (2016) synthesis of CRSL revealed four strands of CRSL that suggest site principals have a crucial role with supporting female student discourse in mathematics. The four strands of CRSL are critical self-awareness, culturally responsive curricula and teacher preparation, school environment, and engaging the community (Khalifa et al., 2016). Teachers can increase discourse in their classrooms when this type 
of leadership is enacted by their site administrators.

Principals need to support opportunities for discourse with teacher preparation that is culturally responsive. This can take place when principals provide the leadership needed to support teachers with increasing student discourse in the elementary classroom. Additionally, principals can intentionally create the time needed within classrooms to develop excellent, high-quality teaching by supporting pedagogical shifts in the classroom so that female students develop agency through mathematical discourse. Engaging female students in mathematical discourse while valuing their thinking can improve student learning outcomes. Principals must empower teachers, as well as educate parents in this area. Principals need to actively engage in public ways of critical self-reflection and self-awareness for this to take place.

Ladson-Billings' (1995) early research on culturally responsive teaching suggested that an important part of supporting students' success is found in the idea of teachers' perceptions of self and others. The teachers in her study believed that all students were capable of academic success. Both teacher and principal mindset correspond to culturally responsive pedagogy and leadership. Ladson-Billings argued for the necessity of teaching codes, as in normalized classroom patterns of speech and behavior in order to help students from diverse backgrounds succeed, thus bridging social discourse to academic discourse. In order for students to succeed, teachers must teach codes. The codes become the patterns of discourse that mark the students' membership 
as learners of math. Her research is furthered by that of Khalifa's (2016) CRSL strand of school environment. Principals can create school environments where the belief that all students are capable of success is reinforced in specific ways with mathematical discourse opportunities.

As a site administrator, social justice leadership is important to me because it is defined as leadership that makes issues of race, class, gender, disability, sexual orientation, and other historically and currently marginalizing conditions in the United States central to advocacy, leadership practice, and vision (Theoharis, 2007). There is a great chance that site administrators will face substantial resistance with change processes, especially those related to social justice and equity. An example of this is shifting instructional practices around discourse. The leadership challenge lies not only in persistence and perseverance, but also in supporting teachers in their own self-efficacy. It is important that leaders have the resilience to persevere on behalf of students to support successful student learning and valid discourse opportunities in math. Site administrators who can identify, understand, and speak out about marginalizing practices with mathematics can shift the discourse in mathematics classrooms by making it central to their advocacy for students. Principals who advocate for students to have agency to speak about math in meaningful ways and allow for mathematics learning to have meaning in students' lives can be true leaders of positive and needed change that can extend beyond the classroom walls. 


\section{Chapter Two: Literature Review}

The literature review contains analysis of important factors that contribute to and shape mathematics learning in the K-12 sphere of education. The literature includes topics within mathematics education such as mathematical discourse, mathematics instructional strategies that are culturally responsive, and teaching strategies that address discourse, mindset, and gender. The literature includes diverse teaching perspectives, as well as the topics of equity and social justice as they relate to mathematics, mathematical identities, and mathematical narratives. Research about girls in science, engineering, and technology were excluded because the scope of STEM is too large.

Three key aspects of effective math teaching and learning relevant to this research project arise from the literature review. The key aspects are pedagogy, also referred to as instructional practices, teacher mindset, and student mindset. Current research provides insights as to how pedagogical shifts, teacher mindset, and student mindset can support marginalized students and their mathematics learning through discourse. A theme within pedagogy found in the literature is that of conceptual and procedural teaching, as well as culturally responsive pedagogy. Culturally responsive teaching relates to enacting teaching practices that enact social justice. Also, a theme within student mindset that is present is mathematical identity and how identity can shape positive learning outcomes. 


\section{Pedagogy}

Pedagogy plays a crucial role in supporting students as they learn math.

Traditional pedagogy expects that students are talked at via direct instruction. However, research does in fact suggest that pedagogical shifts should take place that are more in line with what we know about how people learn. Specifically, students' abilities to make meaning of concepts while engaging in active problem solving versus lecture-type instruction are pedagogical shifts that support learning theory (Willingham, 2009). The ways teachers support students' talking, writing, and interactions with mathematics positions students as belonging or not belonging. Willingham (2009) made the argument that content does not drive interest, rather, working on problems that are at the right level of difficulty is what is key. Therefore, instructional decisions made by teachers are all the more important.

As referenced by Larnell (2016) when explaining the relationship between procedural and conceptual knowledge, "the central pedagogical curricular issue, however, is that too often these concepts are not taught toward developing deep conceptual understanding; instead, rote procedural skills are routinely emphasized at the expense of promoting problem solving and reasoning" (p. 237). Finding a balance between procedural and conceptual knowledge plays a role in pedagogical shifts.

One such pedagogical shift shows that high cognitive demand questions can 
increase student discourse. In their 2015 qualitative study on increasing student discourse through high level teacher questioning strategies that extend opportunities for students to explain their thinking, Martin, Polly, McGee, Wang, Lambert, and Pugalee examined how elementary teachers used high level questions to engage in mathematical discourse with students. The teachers' use of questions and the type of task was analyzed. Teacher/student conversations were coded, and two themes emerged from the research that warrant further investigation.

The first theme revealed that when the teacher allowed for open-ended discussions, discussions of multiple strategies, student-led discussions, and high-level cognitive questions, a higher level of discourse with students took place. The researchers found the use of questioning techniques that created opportunities for students to justify and extend their thinking promoted discourse. The second theme that emerged from the research was that the type of task given had a positive impact on increasing student discourse. Tasks, such as games, allowed for students to explore their mathematical thinking further as they compared their thinking to the different ways of thinking as demonstrated by their classmates. The research focused on questioning strategies used by the teachers that were created by the teachers, not generated by the curriculum. Depending on the questioning strategies used, when a student engaged in discourse with their peers and teacher, it became an opportunity that bridged their native math speak 
with their academic math speak.

Bieda and Lepak (2014) researched how students decided if a mathematical argument given by an anonymous student was valid. This is related to pedagogy because students looked at two written mathematical arguments and used reasoning to decide which argument was credible. Students preferred the use of examples in the arguments because the examples validated the explanation. This was an empowering activity for students because they were given the opportunity to critique the mathematical arguments of their peers. The teachers had to make the intentional pedagogical decision to allow for an opportunity for students to discuss how they make meaning and justify mathematical thinking or how to challenge the arguments of others. Pedagogy is a complex topic with many intricacies.

Procedural and conceptual pedagogy. Instructional decision-making, as it pertains to conceptual and procedural tasks, should seek balance. Conceptual math pedagogies allow for students to demonstrate an understanding of mathematics concepts beyond isolated facts and methods. Procedural math pedagogies allow for students to complete basic computations accurately. It also involves memorizing facts and algorithms.

To further support the research with instructional decisions in regard to the type of task given, Wilhelm (2014) investigated through a longitudinal study focused on middle school teachers, the use of low cognitive demand tasks that were mainly 
procedural and based on memorization of skills. The researcher then compared the frequency of those tasks with the use of high cognitive demand tasks that focused on explanation, justification, and generalization. One result was the greater a teacher's years of experience teaching, there was a higher use of low cognitive demand tasks. Also, teachers who had an inquiry-oriented vision of high-quality mathematics instruction, rather than a traditional vision used high cognitive demand tasks more frequently. Teachers who demonstrated high levels of content knowledge were able to maintain the cognitive demand of high-level tasks within their classrooms.

Discourse as a support for complex teaching. Strategies to support the development of students' discourse provide pedagogical insights to teaching and learning. A qualitative study by Banse, Palacios, Merritt, and Rimm-Kaufman (2016) provided concrete pedagogical strategies found to be effective for teachers to support elementary age English Language Learners with mathematical discourse. A suggested strategy was to "revoice" the student's response so that the student knows his or her voice is a valued and important part of the class community. "Revoicing" allowed for the teacher to elaborate and extend the student's response, as well as demonstrate the use of precise mathematics vocabulary so that vocabulary is no longer a gatekeeper in math. "Revoicing" gave the student an active way to bridge their native math speak to their academic math speak. Additional suggested strategies to increase student discourse are for teachers to model vocabulary in context, engage students in discourse daily, ask open- 
ended questions, and scaffold for students with close-ended questions. A key part of the strategies listed is that they take place daily, therefore, the teacher should have a system in place to ensure that opportunities for discourse can take place routinely.

Opportunities for student discourse amongst marginalized students can increase positive learning experiences that, in turn, position students as part of a learning environment where they actively join and are included in the conversation. Mueller, Yankelewitz, and Maher (2014) investigated how a teacher guided the establishment of the classroom mathematical community through instructional moves that supported students' reasoning and autonomy. The study found that specific teacher moves such as encouraging student explanations and justifications, increased students' confidence in sharing their mathematical reasoning with teachers and peers. Teachers can support students by making pedagogical shifts with discourse practices by focusing on the ways in which students talk and interact with mathematics.

Communication impacts instruction. In a study of two elementary teachers, Khisty and Chval (2002) found that the teacher who engaged in deliberate analyzation of her own mathematical talk was more effective in helping students develop and understand mathematical vocabulary. When teachers make the intentional instructional decision to reflect on and analyze the specific words they use with students, vocabulary development is supported. 
Social justice and culturally relevant pedagogy. A specific strand within mathematics education that corresponds to instructional practices is research regarding the importance of connecting mathematics instruction to students' cultures and lived experiences. This review uses Ladson-Billings (1995) definition of culturally relevant pedagogy, which is defined as follows: Culturally relevant pedagogy empowers students intellectually, socially, emotionally, and politically by using cultural referents to impart knowledge, skills and attitudes.

Ramsay-Jordan (2017) explained how mathematics teachers' expectations were instrumental to student learning, especially in mathematics. The author's theoretical framework was grounded in a core perspective that encompassed Critical Race Theory, counter narratives, Culturally Sustaining Pedagogy, and Culturally Responsive Math Pedagogy. The study demonstrated how the pedagogical shift to teach Culturally Responsive Math Pedagogy (CRMP) came from a place of culturally responsive teaching, while including content integration, the facilitation of knowledge construction, prejudice reduction, social justice, and academic development. Through analyzing personal stories, lesson plans, reflections, and interviews of teachers, the author concluded that inter and intra-personal race relationships both inside and outside of the mathematics classroom were an integral part of the teachers' teaching experiences. In order for learning to take place, teachers in the study challenged Eurocentric curriculum 
and placed high-value on developing positive relationships and rapport with students that were inclusive of students' mathematical narratives. The main finding indicated increased teachers' awareness of racial and cultural issues as it related to the teaching and learning of mathematics. Mathematics instruction that values students' lived experiences, automatically contributes to the development of positive positionality and mathematics narratives.

Mathematics instruction and learning can be analyzed through a culturally responsive lens. In their research on using a culturally responsive mathematics lesson analysis tool, authors Aguirre and Zavala (2013) proposed that social justice education can incorporate mathematics as an analytical tool to understand power relationships and structures of social, economic, and civic issues within a local, national, or global context. Through the analysis of the development of pedagogical decisions and mathematics instruction over time, the researchers concluded that by using a specific tool to evaluate their teaching, teachers were able to engage in systematic analysis and critique of mathematics lessons while giving attention to mathematical thinking, language, culture, and social justice. The lesson analysis tool supported purposeful pedagogical dialogue with teachers when they designed their mathematics lessons. The tool itself was made up of eight dimensions which included intellectual support, depth of student knowledge and understanding, mathematical analysis, mathematical discourse and communication, 
student engagement, academic language support for English Language Learners and use of scaffolding strategies, funds of knowledge/culture/community support, and enactment of critical knowledge/social justice. Along with each dimension there was a reflective question for teachers to answer, serving as a reminder that reflection is a key component to supporting pedagogical shifts. Reflection can be a powerful tool to support students towards internalizing their learning and developing agency.

Research shows instructional practices that perpetuate low expectations. Battey (2013) explored how a group of elementary teachers demonstrated mathematics knowledge and instructional practices in their classrooms, as well as how relational interactions shape access to mathematics for students of color. Elementary mathematics teachers of children with low socioeconomic status were more likely to teach fragmented or unexplained procedures, teach mathematics vocabulary out of context, assess students based on following steps rather than student thinking, and use less resources. In the study, negative relational teacher-student interactions stood out in the areas of addressing behavior and framing mathematics ability when a teacher said in a sarcastic way to the class, "You guys can count, right?" Additionally, the teacher acknowledged student contributions in a passive and negative way when it was observed that she ignored students and rolled her eyes at students. That discourse is a negative one resulting from a negative mindset. 
Research also investigated why teachers are not engaged in culturally responsive mathematics teaching. Ukpokodu's (2011) qualitative study collected information from teachers through interviews and focus groups about their perceptions regarding what culturally responsive mathematics teaching looks like, as well as teacher ideas about why this type of mathematics teaching can be challenging to implement. The data revealed the following issues; teachers view mathematics as a culturally neutral subject; teaching math is convenient because it is dominated by the textbook; teachers feel pressure to teach to the tests; and there is a lack of culturally responsive mathematics teaching models to refer to. Teachers in the study offered ideas about what they thought culturally responsive mathematics teaching practices should look like and seven major themes came from the teachers' responses. The themes generated from the teachers' responses regarding culturally responsive mathematics teaching consisted of deconstructing misguided beliefs about mathematics teaching and learning, integrating culturally relevant content and social and justice issues, utilizing culturally responsive instructional strategies, fostering communal learning, having an openness to students' divergent thinking and problem-solving, de-tracking mathematics classrooms, and developing the teacher's critical consciousness around advocacy and activism. Ukpokodu pointed out that it is inaccurate and insensitive to state that mathematics is a "universal language," rather it is a language unique to each culture. Students' mathematics learning can be 
supported when teaching is culturally responsive.

\section{Teacher Mindset}

Teacher mindset is an existing condition that can be classified as either flexible and growth oriented or fixed and inflexible. This review uses Dweck's (2006) definition of growth mindset, which is defined as follows: In a growth mindset, people believe that their most basic abilities can be developed through dedication and hard work- brains and talent are just the starting point. This view creates a love of learning and a resilience that is essential for great accomplishment (Dweck, 2006). Dweck (2006) goes on to define a fixed mindset as, "People believe their basic qualities, like their intelligence or talent, are simply fixed traits. They spend their time documenting their intelligence or talent instead of developing them. They also believe that talent alone creates success, without effort."

Teacher mindset, whether fixed or growth oriented plays a role in teaching and learning. Wickstrom (2015) investigated how mathematical smartness was framed by teacher mindset and the ways in which teacher beliefs about students learning shaped learning experiences.

Wickstrom's ethno-methodological case study made sense of daily classroom discourses between student-student and teacher-student interactions. Wickstrom found that the teacher in the study held fixed beliefs about her students that impacted instructional decisions, which in turn, limited opportunities for student discourse. The 
teacher's role in the class speaks to the larger issue of the social construction of mathematical smartness in both schools and society. Given the opportunity to reflect on her beliefs about students in her class, the teacher was able to examine her thinking through interviews with the researcher. The teacher came to the realization that viewing mathematical smartness through the lens of labeling students as "good" or "bad" was very limiting. Students may feel that they have little to no say in the development of their mathematical abilities and the teacher plays a powerful role in shaping students' selfperception of their abilities.

Teacher mindset can influence how students position themselves as they learn and engage with mathematics. Cobb and Jackson (2013) further examined how teachers' mindsets can motivate and shape students' learning experiences in terms of how they view themselves as doers of math. In their case study of two Algebra I teachers, Cobb and Jackson found that cultural resources used by the teachers to convey the importance of math beyond school and the relationship to students' lives had a positive impact on student learning. The teachers reported that, "It is not sufficient to just have 'high expectations' for all students to succeed in math" (p.11). The idea of defining students as "people who study in school" was enacted by the teachers. Additionally, the teachers' mindsets supported an empowering opportunity for students to see their mathematical learning towards becoming mathematically proficient as a worthwhile endeavor. 
Similarly, to Wickstrom's (2015) findings, the Cobb and Jackson (2013) study found that teacher beliefs and mindsets about student ability play a significant role in learning. Learning about teacher mindset provides insights as to how teachers view their students, as well as interact with them in the mathematics classroom. Researcher Jackson (2013), analyzed the mindsets of eight elementary school teachers at urban schools. Interestingly, similar themes from the Cobb and Jackson (2013) article were discussed. Jackson found that teachers who had high expectations for students inside and outside of the classroom, as well as teachers who related mathematics to students' lived experiences, and used a variety of instructional strategies allowed for students to position themselves as distinctive people who have mathematical agency. A counter argument is that these practices are relatively rare and there many other practices that are much more common, namely low cognitive demand tasks and activities, that hinder mathematical agency.

There is a relationship between teacher's math identities and how they teach mathematics. Researchers McCulloch, Marshall, DeCuir-Gunby, and Caldwell (2013) explored teachers' math identities as socially constructed and constantly changing as teachers interacted within the different communities in which they live, work, and learn. Individuals' math narratives shape and form the way people interact and position themselves in the world, thus, connecting them to teaching mathematics. The study 
found that the teachers' math narratives impacted their attitudes towards mathematics as either generally positive or generally negative.

Teachers' experiences shaped the way they taught math, because the teachers expressed enthusiasm or apprehension towards teaching math. Their expression of enthusiasm or apprehension in relationship to teaching math was tied to their positive or negative experiences with mathematics prior to teaching. Teachers who had experienced a combination of positive and negative mathematics experiences expressed confidence and positivity towards teaching math. Teachers who had mostly negative experiences, expressed apprehension and uncertainty towards teaching mathematics. The study showed that past experiences shaped teachers' attitudes towards teaching math.

\section{Student Mindset}

Just as teacher mindset toward mathematical learning impacts teaching methods and interactions with students, student mindset can directly impact math learning outcomes. Mindset is a component of mathematical identity. Mindset, as it relates to students, can generally be described as students believing that they are the mathematical authority and seeing themselves as competent learners (Langer-Osuna, 2017). Research has described what this looks like, how it is developed, and the impact it has on student learning.

The way in which students view themselves as doers of mathematics impacts their 
confidence and learning. Student mindset revealed itself through Dunleavy's (2015) research, which explored discourse as "mathematical authority" and students' positionality as learners of math in relationship to their authority and identity in the classroom. Dunleavy studied student mindset in the classroom and how it related to discourse. Student presentations, Shuffle Quizzes, and Participation Quizzes were found as a successful support towards positive student mindset because they were used to position students as competent, as well as to have students justify mathematics, and to allow for students to work with one another. The research provided valuable information about how to increase opportunities for students to engage in meaningful opportunities for discourse such as talking, writing, and interacting. Equitable discourse is dependent on how students' identities as learners are established as they participate in classroom mathematical practices.

The ways in which students use language in the mathematics classroom can support a positive mindset. Simpson and Cole (2015) analyzed the academic language of math in order to further understand discourse in the mathematics classroom. Their research intersected with students' mathematical positionality in terms of their mathematical identity. Students' identity related to mathematics, often exists as a binary of being "smart/good" or "dumb/bad" at math through the ways in which students speak to each other about math. An implication of the study was explained as, 
"mathematics educators must do more than teach vocabulary for students to successfully appropriate the language of mathematics, and teachers play pivotal roles in the establishment of norms, and acknowledgement of idiosyncratic student identities and understandings in the classroom" (p. 114). If students receive support positioning themselves as having positive mathematical identities, they may experience positive learning outcomes as well.

Student identity is tied to the development of student mindset. Nasir (2002) researched how relationships between identity, goals, and learning can help us understand the dynamics of race, culture, and math learning as it relates to student mindset. Nasir made the following conclusion after observing students play dominoes, "When mathematical goals arise in the context of activity, the mathematical operations become a normal and required part of the cultural practice" (p. 97). Nasir's research suggested that further discussion in the area of how school environments support students' developing identities and mindsets is needed.

There is a need for students to engage in verbal discourse in order to develop positive mathematical mindsets. Mueller and Yankelewitz (2014) examined how incorrect answers were discussed in a study of fourth grade and sixth grade classrooms. The results showed that students gained a deeper understanding of mathematical concepts in their discussions about incorrect answers. The study supported the idea that the 
sharing of arguments can strengthen students' mindsets because students had the opportunity to defend and justify their own thinking with multiple representations of their thinking. The ways in which students interact with each other in the classroom contributes towards building a positive mindset.

Mathematical identity. Students' mathematical identity shapes their mindsets. Nasir and Cobb (2002) provided commentary to understand the link between broad societal structures and equity within classroom interactions. The researchers found that student identity as it existed in the mathematics classroom was typically not valued. They pointed out that race and culture play out in subtle ways in mathematics classrooms, which, in turn, creates inequitable academic outcomes for students. The goal of the article was to help to reframe issues of equity in mathematics education and to enrich understandings of the process by which marginalized learners experience mathematics education. Equity depends on how students' identities and mindsets as learners are established as they participate in classroom mathematical discourse practices such as talking, writing, and interacting with their peers and teachers. Identity plays a significant role in learning. The article pointed out specific ways in which standardized tests and traditional instructional practices disguised as reform-oriented privilege the achievement, mindset, and identity of upper and middle-class white students.

Identity is inextricably tied to students' cultures. Students who experience a 
school culture that both values and corresponds to their home culture are automatically set up for success (Langer-Osuna \& Nasir, 2016). If the ways in which students communicate in the mathematics classroom are valued, their identity is positioned as a positive one. Furthermore, students' development of their intellectual authority as it relates to communication with their peers supports positive mathematical identity (Esmonde \& Langer-Osuna, 2013). The researchers go on to explain how there is very little explicit talk of race or gender in mathematics classes, but the classroom continues to be racialized and gendered. When a student's race and/or gender is not acknowledged and valued, the development of a positive mathematics identity remains uncertain. As previous literature suggests, student mindset is identified as positive or negative. The same is true about mathematical identities. Anderson (2007) used social learning theory to make the claim that the development of a positive mathematics identity results from four faces of identity which are: imagination, nature, engagement, and alignment. The faces are reflective of students' lived experiences and focusing on one face, such as engagement, can support the development of strong positive mathematical identities for all students. Both mindset and identity can be flexible and shift between positive and negative stances. When students experience positive mathematical learning opportunities, they can be successful in math. 


\section{Significance of Gender}

Gender plays a role regarding children's identities and their experiences in the elementary math classroom. Current research shows gender differences in specific areas of achievement and participation. Aragon, Serrano, and Navarro (2018) completed a qualitative study in which a gender achievement gap in mathematical fluency presented itself at age nine in students who participated in the study. Additionally, Reinholz and Shah (2018) analyzed how girls remain marginalized with respect to their opportunities to participate in discourse. Rimm-Kaufmann, Baroody, Larsen, Curby, and Abry (2015) explained how elementary age male students have increased academically challenging interactions with their teachers when compared to female students. All of these experiences create differences in student engagement within the mathematics classroom. It is undeniable that gender plays a role in the elementary mathematics classroom.

Gender plays a role in mathematics participation and attitudes. Tichenor, Welsh, Corcoran, Piechura, and Heins (2016) studied the role of gender as it relates to mathematics participation and attitudes. Their findings revealed increased participation and positive attitudes of third through fifth grade girls due to the culture of the school. Through student surveys, their study revealed that students experienced differentiated instruction which was unique to the specific needs of male and female students. The school culture as related to mathematics instruction supported positive attitudes and 
increased participation outcomes for female students. Teachers participated in professional development opportunities that used research on gender differences and related it to specific teaching strategies. This study is evidence of a promising strategy to promote gender equity in mathematics.

While this study depicts proactive and positive approaches to support female students math participation and attitudes, it is often the case that students have experienced gender conditioning as it relates to mathematics prior to fifth grade. Cvencek, Meltzoff and Greenwald (2011) found that as early as second grade, children demonstrated an American cultural stereotype that math is for boys. Their study also revealed that elementary school boys identified with math more strongly than girls (Cvencek et al., 2011). Given that research shows gender stereotypes as early as second grade, the negative effects on participation, attitudes, and achievement is far reaching in later grades and beyond. Effective professional development for teachers is one way to make change that supports positive attitudes and increased achievement for female students.

Many factors contribute to female students' experiences in math. Leaper, Farkas, and Brown (2012) explored ways to support female students' success in mathematics. The study found that positive social and personal factors can strengthen adolescent girls' motivation in math. Female students reported positivity and motivation towards 
mathematics when they received peer support. The study found, "When peers are viewed as valuing math and science, girls may be more likely to perceive these subjects as selfrelevant during identity exploration" (Leaper et al., 2012). Peer influences impact the development of positive mathematical attitudes.

Structures in place can support the development of positive identity for female students. Joseph, Hailu and Boston (2017) found that structures such as cocurricular programs can support the development of high motivation, persistence and mathematics identity for black women and girls in mathematics. Their research further concludes that women need to be included in mathematics in the following ways: solving grand challenges in mathematics and expanding mathematics leadership and decision-making (Joseph et al., 2017). Including voices of women is central to supporting change.

Although teachers are well intentioned, their perceptions and their lack of awareness of their roles in advancing African American girls as science and mathematics learners in many ways limits the opportunities afforded to these students (Joseph et al., 2017). Their study found that many teachers were not able to adapt their pedagogical practices to meet the perceived needs of their learners. This corresponds to the literature that pedagogy and teacher mindset play a role in supporting female students' development of positive mathematical identities.

As research suggests, gender plays a significant role in math classrooms as related to participation. Additionally, girls' participation and achievement is dependent on many 
factor such as instructional practices and peer influences.

\section{Conclusion}

Learning math is complex and more research needs to be done to support opportunities for students to engage in mathematical discourse in the classroom. In the research itself, almost all of the studies reviewed center on teacher interviews. Student classroom experiences, in particularly, at the elementary level are missing and not included. While female students have received attention in mathematics because of STEM opportunities and differences in achievement level, their voices are missing from the research.

In terms of equity and student discourse, when all students, especially, female students, are given the time and space to explain their thinking, there is a need for every student in the instructional activity to be acknowledged as a distinctive member of the math community. The literature suggests that effective teacher questioning can facilitate students' mathematical discourse opportunities, as well as the development of positive student identity and attitudes in relation to mathematics. When students have opportunities to engage in meaningful mathematics discourse, it promotes self-agency that will benefit students beyond their educational experiences. The intersectionality of discourse with curriculum, instructional decisions, student engagement, and school environment can further the understanding of math teaching and learning as it relates to female students and the development of their identity and mindset. 
What can be gathered from the current research in terms of gaps is basically twofold. The first identified gap is that the voices of elementary female students is missing. In the elementary school setting, there exists a large void absent of female student voices and more information needs to be provided about how females students internalize their mathematics learning. Student voice is key towards establishing an understanding of how students experience mathematics in the classroom. While not totally absent from the research, how female students experience math needs to be investigated further. Additional research that specifically includes female student voice can shed light on how female students successfully learn math in the elementary classroom.

The literature relates to my research because including the voices of female students will connect and add to the key aspects of mathematics learning, thus informing pedagogy and how to support positive mindset and attitudes towards mathematics unique to female students. Takeaways include the need to find a balance between conceptual and procedural mathematical tasks, as well as investigating pedagogies that allow for students lived experiences and cultures to not only exist, but have value and respect in the classroom as well. 


\section{Chapter 3: Methodology}

This qualitative study examined how fifth grade female students experienced the teaching and learning of mathematics. Fifth grade male students were included in the study as a point of comparison, not as a broadening of the study aim. The study compared both male and female experiences and provided insights as to what educators can do, specifically, to support female students in the mathematics classroom and beyond. Current research provided valuable information about how to increase opportunities for students to engage in meaningful learning that supports discourse as it is related to talking, writing, and interacting. This study added to the existing research by documenting children's perspectives on how they experienced the mathematics classroom. The study also added information as to how students interpret supporting and challenging pedagogical structures that they have experienced and currently experience. In addition, the focus on girls is particularly important because their voices and experiences added meaningful value to the data. The research methods of this study supported the research question.

The purpose of this qualitative study was to examine the discourse of female students in two fifth grade elementary classrooms in terms of how they think, talk, and write about mathematics, using male students as a reference point. A goal of the study was to gather a better understanding of how female students learn math. This 
understanding was then related to the students' attitudes towards mathematics. There are many known instructional moves and shifts that engage and differentiate learning opportunities for students, however, there was value in finding out what the students though about learning and doing math. The voices of fifth grade female students are missing from current research, therefore, this study added their voices.

The conceptual framework directly supported the methodology. Student mindset, social discourse, and academic discourse was analyzed through student interviews and focus groups. Teacher mindset, academic discourse, and social discourse between teachers and students was evidenced through classroom observations. Student writing samples represented academic discourse and student mindsets towards math. Each of these informed the central aspect of the conceptual framework, which was mathematical discourse and attitudes. 


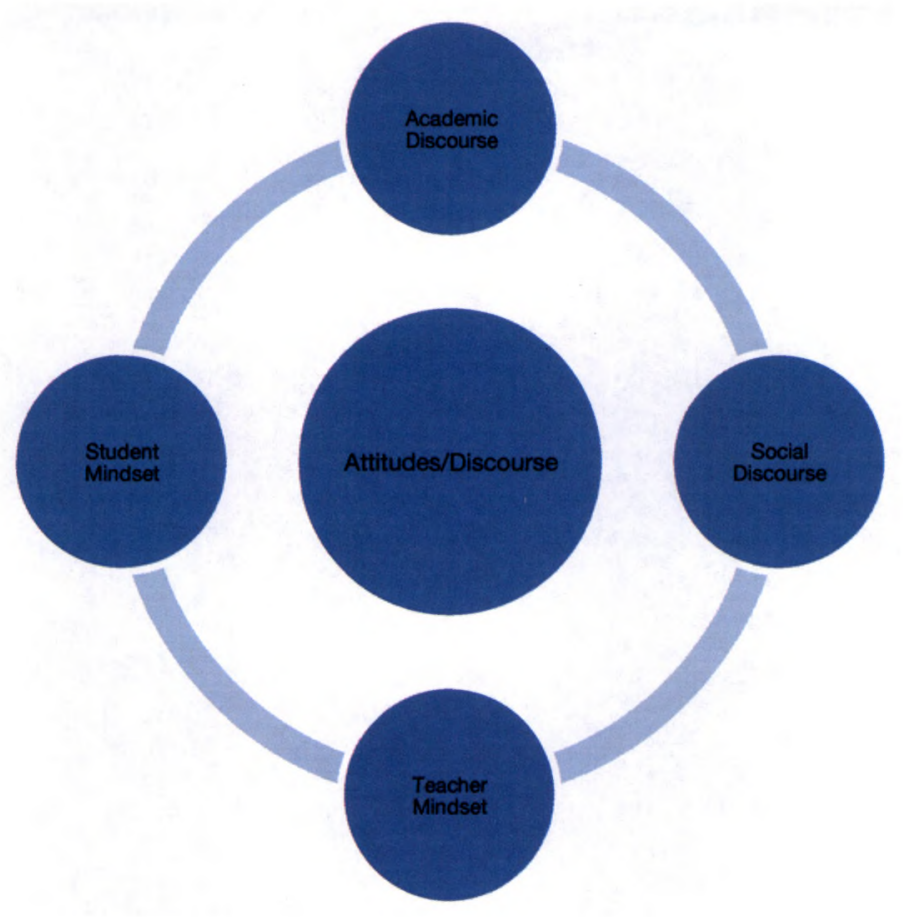

Figure 2. Math interconnections across discourses and mindsets.

\section{Context of the Study}

The data was gathered from fifth grade female and male students at Oak

Elementary School ${ }^{1}$. The school was located in a suburban setting in Northern

California, where $83 \%$ of the students were classified as socio-economically

disadvantaged, $70 \%$ were Latinx, and $46 \%$ were English Language Learners.

The 2017 CAASPP (California Assessment of Student Performance and Progress)

fifth grade math results from the school showed that only $15 \%$ of socio-economically

disadvantaged students met or exceeded standards, while $74 \%$ percent of students not

${ }^{1}$ This is a pseudonym; all names have been changed to protect privacy. 
socio-economically disadvantaged met or exceeded standards. Similarly, $6 \%$ of English Language Learners in fifth grade met or exceeded standards. CAASPP mathematics data showed almost equal lack of achievement between male and female students with only $34 \%$ of female students and $33 \%$ of male students meeting or exceeding standards. In third, fourth, and sixth grades male students outperformed female students, which was different than the national scores where girls outperformed boys through eighth grade. Additionally, the percentage of female students meeting, or exceeding standards increased over time, while the percentage of male students meeting, or exceeding standards decreased over time.

CAASPP data is useful but not comprehensive in that it does not account for overlaps within the subgroups. For example, a student could be female and socioeconomically disadvantaged; or female, Latinx, and socioeconomically disadvantaged. However, it is indicative in proving the existence of a learning gap that negatively affects English Learners and students who are socioeconomically disadvantaged. The lack of difference in standardized test scores between males and females differs from national statistics. Prior research indicates that despite the similarity in achievement, girls still develop more negative ideas about math and themselves as math learners. While prior to the study it was not known if the students at this school matched the national findings, test statistics are comparable to broader findings. 


\section{Research Question}

The research question for this study was, "How do instructional practices that fifth grade female students experience at school support and relate to the development of positive mathematical attitudes?"

\section{Role of the Researcher}

In the months leading up to this study, I was hired to be the principal at a new school. Through my leadership position as the new site principal at Oak Elementary School, I was able to quickly establish positive working relationships and rapport with teachers and students through informal and impromptu meetings. At our first staff meeting, I shared with staff that mathematics education is one of my passions, as well as my work in this area over the past two years at San Francisco State University. My newness to the position allowed for students to speak candidly with me about their experiences learning mathematics. I am a supportive presence in the classroom, especially to students, when I am present in their math classes. The fact that I am new to the school this year, will support unbiased data analysis.

My position, however, undoubtedly impacted what the children said, given they were speaking to their principal. While I was new to this school, I was an elementary school principal over the past four years at a different school and I have spent time in classrooms teaching and modeling effective mathematics instruction that focused 
on developing academic math language, as well as teaching students how to revise and extend their thinking. Additionally, I have chaired K-12 District Math Committees. Chairing these committees has included many leadership endeavors such as writing district-wide math visions, piloting new curriculums, and implementing formative benchmark assessments.

I am most interested in mathematics education as a vehicle to enact social justice and equity as it relates to the success of female students. The topic of female students in mathematics is of particular interest to me because mathematics has opened many doors for me professionally. It is my hope that this work results in mathematics no longer being a gatekeeper for students, especially female students. This dissertation supported the enactment of culturally responsive school leadership practices to create the needed and necessary space for mindset and pedagogical shifts to occur. Everyone knows that I love math!

\section{Research Design}

The research design was a qualitative case study analysis of fifth grade female students' development of mathematical identities. Data and information from the male students was used to make comparisons and draw correlations across and between genders. The design came from an analysis of how the students experienced opportunities for mathematical discourse in their classrooms. Data were collected 
through student interviews, student focus groups, student work, classroom observations, and assessments. The data were analyzed through qualitative coding methods in order to understand and make sense of patterns that revealed topics and themes relevant to the research question (Charmaz, 2014). The detailed narrative accounts provided evidence into children's experiences and was then connected to grounded theory regarding the development of mathematics identity. The data answered the research question because it allowed for an analysis of fifth grade female students' experiences in mathematics classrooms as related to developing and supporting positive mathematical identities. The significance of this research to the educational field provided insights to educators from the students' perspectives about how to develop and support positive mathematical identities specific and unique to female students through the development of their mathematical discourse.

\section{Participant Selection}

The participants of the study were eight fifth grade female students, and nine male students from two public school classrooms at Oak Elementary School. Forty-three permission slips were given to the participants. Seventeen permission slips were returned, twenty-six permission slips were not returned. The total enrollment of fifth grade students at the school was forty-three students, twenty-two students were female, and twenty-one students were male. All participants who met the requirement of being a 
fifth-grade female or male student at Oak Elementary School and those who returned a permission slip were allowed to participate in the study. The total number of research participants did not exceed seventeen. The age of all students at the time of the research was ten years old. The participants were considered to be a vulnerable population because they were children. No students had Individual Education Plans (IEPs). Fifteen students were Latinx and of those fifteen, four were English Language Learners (ELLs). No students had special needs that directly impacted their participation in the study. Translated letters were made available for students and parents.

The participants were already known to me because they were students in classrooms in the school at which I was the principal. Participants were selected based on their current grade level, all other grade levels were excluded. To recruit students for the study, I delivered a brief speech in classrooms explaining the study. I then sent home a letter with students explaining the purpose of the research and asking parental permission to work with children. Recruiting materials were attached in Appendix A and consisted of a hard copy letter text, as a simple invitation to participate in the study. Because the opportunity was offered to all fifth-grade students, and because fewer returned signed forms than my maximum of twenty, I did not engage in further sample selection. 


\section{Ethics and Protection of Human Subjects}

The Institutional Review Board (IRB) at San Francisco State University has reviewed and approved the use of human subjects in this research project. A number of precautions were taken to protect the participants' privacy and ensured that no harm to participants resulted from participation in the study. If, at any time, a student exhibited stress or anxiety, the risk was minimized by excusing the student from participation. However, no participants exhibited stress or anxiety, and no one was excused from participating. Loss of privacy was minimized by conducting interviews out of the hearing range of others. As the principal of the school, the potential perceived risk to participants was increased, however, I have been present in students' classrooms reading books and introducing myself as the new principal.

A coding system that was made up of numbers and letters unique to each student was used to protect the privacy of the students and the security of the data. Student names were removed from all work samples collected for this study and were replaced with the identifying letter/number combination. The key connecting students to their identifying letter/number combination included only the first names of students, and last initial in the case of duplicate names. 


\section{Data Collection}

I collected data from five sources- student work represented as written prompts, focus group interviews, one on one interviews, classroom observations, and formal mathematics assessment data. Each data source served as its own unique way to contribute to answering the research question. The data sources are listed and explained in Table 1 and have an intentional ordinal sequencing. All written prompts, focus group questions, and interview questions were located in Appendix B. All data sources provided additional information that corresponded to all sources included in the resource methods.

Data was collected during the regular school day in September 2018-October 2018. Focus group interviews and individual interviews took place on the following dates: September 11, September 18, October 2, October 9, and October 23. Math centers took place on Tuesdays from 8:45am-10:00am. The time of day that the focus groups and interviews took place was during part of the math centers from 9:30am-9:50am. Classroom observations took place on the following dates: September 28, October 17 , October 22, and October 26. Classroom observations lasted for a period of thirty minutes. Student responses to a written prompt were collected on observation dates. The work was coded in order to analyze similar themes that emerged from the student work in relation to the coding of student interviews, focus groups, and classroom observations. 


\section{Students' Responses to Written Prompts}

The prompt served as a warm up to allow for students to begin thinking about their experiences learning mathematics. The written prompt was used as a way to support students' initial experiences discussing mathematics and to alleviate stress from beginning participation in the research with a cold interview. Based on the literature review, I operated under the assumption that students in this study had little to no experience being a part of math interviews, especially math interviews that ask them about their experiences learning math. Having been an elementary school principal the past five years, at two different sites, I have not observed or heard any discussions around interviewing students about mathematics.

The math interviews were a new experience for students. The teachers of the classes gave the prompt to all students during the class math center time. Only prompts from students participating in the survey were used. Student work allowed for student voice to be heard through their writing. Students had the opportunity to write about their mathematical experiences and learnings.

\section{Focus Group Interviews}

The purpose of the focus groups was to support the students to talk more freely and in greater detail with each other. The one on one interview setting could unintentionally limit what students said. Based on what the students said in the focus 
groups with each other, the participants added additional information that they had not thought of talking about during the writing prompt. Focus groups were conducted by the researcher and took place during the math centers. To further conversations with focus groups, students watched an instructional video of a different fifth grade classroom as a third point reference where they commented on what they thought worked and did not work for the learners in the classroom where the video was filmed. There were four or five students in each focus group. The teachers of each class worked with me to create math groups in which students participating in the research were grouped together. The focus group math center groups rotated through the math centers just as all of the other math center groups did. The focus groups' interviews were audio recorded. Focus group questions provided additional information. The data was triangulated across multiple data sources through addressing questions of validity and generalizability through transferability.

\section{Individual Interviews}

The student interviews took place with students one on one during the instructional day as a mathematics center. I conducted the interviews with students in the classroom. The interviews were audio recorded and transcribed. Questions for student interviews are located in Appendix B. Both individual and group interviews followed a semi-structured interview group format. Questions were asked based on former trial 
responses. Student interviews allowed for patterns and themes to emerge that were unique to student voice. The purpose of the student interviews was to further understand student thinking, as well as to understand the ways in which students were able to extend their thinking. The interviews are represented as a first cycle of codes based on Charmaz (2014) initial coding for topics and themes. The interviews allowed for student voice to exist in the research and supported answering the research question.

\section{Classroom Observations of Focus Students}

The fourth data source was classroom observations of certain students in the research study. Based on students written and verbal responses, I chose two students to observe more closely in the classroom. The classroom observations took place during the regularly scheduled mathematics instructional time. The purpose of the observations was to focus on what the research participants were doing and saying in the mathematics classroom. That information corresponded to and supported the existing patterns and themes in the written prompts and interviews. Classroom observations consisted of data memos written by the researcher.

\section{Formal Mathematics Assessment Data}

The final data source was student assessment data. This data was made up of an end of unit assessment from the Bridges curriculum and the 2017 CAASPP mathematics scores. This data added to student identity and the student reported mathematical 
learning experiences. The data revealed patterns about what the students said or wrote in previous data collection.

Table 1

Data Collection Information

\begin{tabular}{|l|l|l|}
\hline Data Source & Analytical Method & $\begin{array}{l}\text { Connection to } \\
\text { RQ }\end{array}$ \\
\hline $\begin{array}{l}\text { 1.Student responses to written } \\
\text { prompt. }\end{array}$ & $\begin{array}{l}\text { Coding for data analysis of } \\
\text { patterns and themes. }\end{array}$ & $\begin{array}{l}\text { Student } \\
\text { responses to } \\
\text { written } \\
\text { prompts } \\
\text { served as a } \\
\text { warm up to } \\
\text { get students } \\
\text { initially } \\
\text { thinking } \\
\text { about their } \\
\text { experiences } \\
\text { learning } \\
\text { mathematics. }\end{array}$ \\
\hline 2. Focus group interviews. & $\begin{array}{l}\text { Coding for data analysis of } \\
\text { patterns and themes. Audio } \\
\text { recorded/transcribed. }\end{array}$ & $\begin{array}{l}\text { Students } \\
\text { shared } \\
\text { information } \\
\text { about } \\
\text { instructional } \\
\text { practices. }\end{array}$ \\
\hline $\begin{array}{l}\text { 3. Individual student } \\
\text { interviews. }\end{array}$ & $\begin{array}{l}\text { Coding for data analysis of } \\
\text { patterns and themes. Audio } \\
\text { recorded/transcribed. }\end{array}$ & $\begin{array}{l}\text { Students } \\
\text { shared } \\
\text { information } \\
\text { about } \\
\text { instructional } \\
\text { practices and } \\
\text { mathematical } \\
\text { experiences. }\end{array}$ \\
\hline
\end{tabular}




\begin{tabular}{|l|l|l|}
\hline $\begin{array}{l}\text { 4. Classroom observations of } \\
\text { focus students. }\end{array}$ & $\begin{array}{l}\text { Analysis of points of match } \\
\text { and seeming mismatch } \\
\text { between students' written and } \\
\text { interview responses and } \\
\text { observed mathematical } \\
\text { behaviors. }\end{array}$ & $\begin{array}{l}\text { Focus } \\
\text { students were } \\
\text { observed } \\
\text { participating } \\
\text { in } \\
\text { mathematics } \\
\text { lesson. }\end{array}$ \\
\hline 5. Student assessment data. & $\begin{array}{l}\text { End of unit assessment and } \\
\text { CAASPP. }\end{array}$ & $\begin{array}{l}\text { Discovered } \\
\text { correlations to } \\
\text { achievement } \\
\text { and student } \\
\text { interview/foc } \\
\text { us group } \\
\text { responses. }\end{array}$ \\
\hline
\end{tabular}

\section{Data Analysis}

The data was analyzed through coding. A code was counted if the key words were repeated more than once by more than one student. The purpose of this qualitative study was to find out about the discourse of female students in two fifth grade elementary classrooms in terms of how they think, talk, and write about mathematics, using male students as reference and comparison points. The data was coded, and specific patterns were analyzed. Themes were identified through emergent coding of positive, negative, or neutral attitudes towards mathematics and experiences in the classroom as they relate to mathematics. The data was coded as positive, negative, or neutral and supported the development of mathematical narratives unique to the research subjects. It was decided that codes were significant, or to be counted, when the theme of positive, negative, or neutral was repeated by the research subjects. 
Validity of identified codes was checked by having a colleague read through the data and code based on the codebook I had developed. This was done without direct input from me. The colleague coded with the codebook and had $80 \%$ similarity. Narratives were developed through the coded data through the development of a codebook. The codebook was developed through common and repeated words and phrases. From the words and phrases, themes with positive and negative iterations were developed. Finally, code categories were developed. The progression was to analyze the student writing samples, followed by the focus group interviews and individual interviews. Mini case studies of two focal students from classroom observations were then discovered. Finally, adding student assessment data as a final data point allowed for the discovery of trends and conclusions.

The findings are credible because focus groups and classroom observations coincided and corresponded to the information that was acquired through student interviews (Charmaz, 2014). Student interview questions focused on student feelings towards mathematics, change ideas that students had about mathematics, analysis questions concerning how students have experienced math, and focus group questions that developed an understanding of the female experience in the elementary mathematics classroom (Peavey, 1997). Students were asked about their experiences with mathematics outside of the classroom. This information provided background 
information that affected student classroom experiences. Student experiences were gathered through a brief writing opportunity where student work was collected. The information that students shared added insights that related to developing and supporting positive mathematical identities for female students. Credibility was established because different data sources were checked against each other.

The reliability of the study dealt with consistency and the study was reliable because all of the students answered the same questions and participated for equal amounts of time during the focus groups. Focus groups were used to supplement the interview data to find out how students' experiences inside and outside of the mathematics classroom added to the researcher's information and are represented as a first cycle of codes based on Charmaz (2014) initial coding for topics and themes. All questions asked directly related to the research question. The research methods provided valuable information to answer the research question, valued student voice, and supported mathematics instruction. 


\section{Chapter Four: Findings}

This chapter analyzed the five data sources via coding, patterns, and themes. The data were in the order in which the story developed. Written prompts were analyzed first because they were the "warm-up" to get students thinking about math learning, as well as their math experiences. Focus group interviews were analyzed second because it was the first time students were interviewed about math. A group setting was a less intimidating place to start than one on one interviews with the principal. Individual interviews were third because I could revisit specific things students had mentioned in the focus groups. Classroom observations were fourth because the prior analysis suggested which students the classroom observations were centered on. The last data set that was analyzed was the student assessment data. The five data sets were used to develop case studies about specific students.

\section{Analysis of Written Prompts- Female}

The first data source was collected through written prompts. Having the students write their thoughts about math prior to speaking about it served as an initial warm-up to get students thinking about math in ways they do not usually talk or write about it.

The tally chart in Table 2 showed frequencies of students likes and dislikes in math. Students listed eleven things they liked about math and five things they did not like. Female students had a more positive tone than compared to male students. 
Fourteen out of eighteen total responses from female students were positive and only five out of eight responses from male students were positive. Female students also wrote more likes about mathematics than the male students. Both female and male students wrote the same amounts of dislikes regarding math. Female students wrote about mathematics in a more positive tone with a greater number of ideas.

Table 2

Student Writing Prompt Data

\begin{tabular}{|l|l|}
\hline Likes & Frequency Male/Female \\
\hline Addition & 1 (male)/3 (female) \\
\hline Subtraction & 1 (male)/2 (female) \\
\hline Multiplication & 1 (male)/1 (female) \\
\hline Division & 1 (male) \\
\hline Getting the answer & 1 (female) \\
\hline Learning math & 2 (female) \\
\hline Everything & 1 (female) \\
\hline Group work & 1 (female) \\
\hline Learning a new strategy & 1 (female) \\
\hline Homework & 1 (female) \\
\hline Being challenged & 1 (male)/1 (female) \\
\hline
\end{tabular}


Table 2

Student Writing Prompt Data

\begin{tabular}{|l|l|}
\hline Dislikes & Frequency Male/Female \\
\hline Division problems with remainders & 1 (male)/2 (female) \\
\hline Not getting it & 1 (male) \\
\hline Extra work & 1 (female) \\
\hline People expect too much & 1 (male) \\
\hline Separated students into ability groups & 1 (female) \\
\hline
\end{tabular}

Some examples of positive female tone from the written prompt were:

"Math is fun for me when I get a hard task. One of the things I like to do in math is working in a group. I like working in a group because if someone does not get

it, I get to help them out. I like helping people out" (Jane).

"My thoughts are, I love when you learn a new strategy"(Amelia).

"What I like about math is that it is fun to learn new stuff. It can be challenging, but it is worth it" (Stacy).

The female voices captured a diverse array of ideas. One of the ideas that stood out was the idea of being challenged. Jane, Amelia, and Stacy all gave different positive examples of being challenged. Jane described completing, "hard tasks," as a math activity she always looked forward to. Amelia's was, "learning a new strategy." Stacy 
wrote, "to learn new stuff." Hard tasks and new learning are all examples of demands

from the female students requesting high expectations from others and a desire to be challenged.

Some examples of negative female tone are:

"The thing that I do not like about math is dividing. I think it is really hard for me to divide because there are sometimes remainders" (Sarah).

"One thing I dislike about math is doing extra work when we don't need to" (Amelia).

The dislike of division with remainders came from a lack of understanding of what the remainder meant. Both genders expressed negative feelings towards division regarding remainders.

\section{Male Student Responses}

Some examples of positive male tone are:

"The thing I like about math is to add, subtract, and multiply numbers" (Jack).

"I like that math challenges me" (Conor).

Conor's response is similar to the female responses because he likes to be challenged by math. Jack's response was a common one given by the male students that references basic computations. 
Some examples of negative male tone are:

"I don't like that sometimes people expect too much of me" (James).

"The thing I dislike about math is division problems because of the remainders it has" (Sean).

James's response is opposite from the female theme of high expectations. He was explaining his general experience that people have too high of expectations for him in mathematics. Sean's response was also written by two female students.

\section{Analysis of Focus Group Interviews}

Focus group interviews served as a way to have students discuss mathematics in a small group. The intention of the focus group was to help the students be more at ease and comfortable during the upcoming one on one interviews. Focus groups led to rich conversations led by students' voices. There were four focus groups with male and female students in each group. The focus groups each had four or five students. Students participated in two rounds of focus groups.

\section{Focus Group One: Attitudes Towards Math}

In the first round of focus groups, students were asked questions about how they best learned mathematics, as well as questions about their attitudes towards mathematics. Focus group questions are located in Appendix B. In the second round of focus groups, 
students watched a video of a math lesson and were asked questions regarding the video.

The first focus group interview themes were coded by gender specific to emerging patterns. Table 3 depicts focus group interview responses by gender. Student responses are listed as positive frequencies. Specifically, one female student reported a positive home experience related to math, whereas six male students reported positive home experiences related to math. Therefore, male students demonstrated a generally positive trend towards the theme of positive home experiences related to math. Female students expressed a more frequent appreciation of receiving help from the teacher when compared to male students. Female students expressed more frequent enthusiasm towards learning new strategies and being challenged. Both male and female students expressed similar amounts of noticing differences between gender participation. 
Table 3

Focus Group Response Themes by Gender

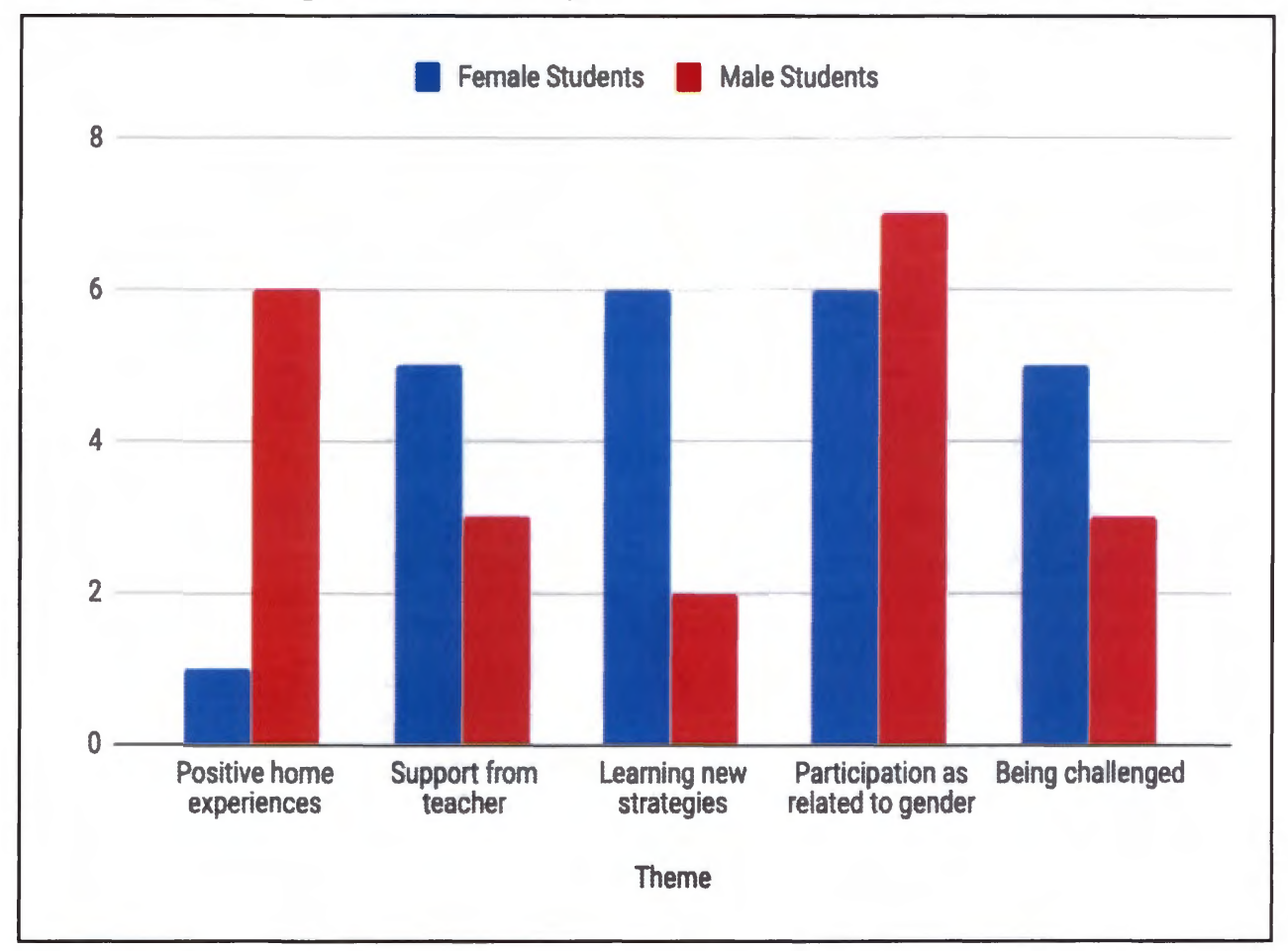

Some female and male students indicated positive experiences with mathematics when their teacher helped them learn a new skill such as multiplication. Students indicated that using different strategies such as stacking, mental math, and traditional algorithms helped them experience positive learning in regard to math. Liz reported that she did enjoy playing math games at school because the strategies she used helped her win the game.

An interesting part of the focus group interviews took place when male students typically reported positive home experiences related to math, whereas female students reported negative home experiences related to math. The male students talked about 
how, at home, they played fun math games with family members. Conor said, "A positive experience that I've had was me and my uncle were playing Connect Four. And I won. I love math because a lot of games have math in them." Female students expressed frustration around family members not helping them with their homework and not getting the support they needed to get their work done. Male students reported positive home interactions regarding math, while female students reported feeling unsupported at home.

Multiple female and male students in the focus groups pointed out that division had been an overall negative experience for them because there was a high level of frustration around dealing with division problems with remainders. Bree stated:

It's like they said, remainders, because it's really hard to find remainders because sometimes it could be 0.2 something or like 0.2 and a half something remainder. And it could be really hard to find what it is. And one time I did an equation where I had to find eleven divided by twenty-eight. And I thought it was really hard, and at the end, I thought that it was 2.8 remainder, but it actually wasn't. And so I got super frustrated, because it's hard to find remainders. Similarly, both male and female students expressed stress and frustration towards having to complete basic math facts for addition, subtraction, multiplication, and division in a certain amount of time. 
Student focus group responses to what they like about mathematics corresponded to what they had written in the initial writing prompts. The same likes and dislikes were brought up again and elaborated on. This was interesting because students did not have their writing prompts with them during the focus group interviews. Amelia gave the following response regarding her mathematical likes:

I love like, getting challenged, and like, let's say we had a really, really hard equation, I like getting challenged, and see if I got it right or wrong. And I also like to know, let's say we have a really, really hard math problem, I like to solve it by myself and see if I got it right or wrong and learn from my mistakes.

Her response demonstrates the beginning of an integral theme mentioned by two female students. The theme of being challenged was brought up by female students throughout the research when compared to male students.

Additionally, both focus groups reported gender differences in the classroom in terms of who was called on. Female students discussed how the boys would get called on, because they tended to be somewhat unfocused and distracted. They discussed how teachers called on them to make sure they were paying attention. Sarah said, "I'll have my hand up and I won't get called on, so then I just put my hand down." The male students were agreeable to that, and did not disagree. The male students collectively 
responded, "Yeah. That's kind of how it goes." A general inference was that this was an experience that students had become familiar with over a longer period of time than just fifth grade.

During the focus group interviews, both male and female students were agreeable to each other's responses and added to them. Different kinds of classroom management techniques, in terms of who participated in a whole class setting was reported by both genders. Females reported they like being called on by their teachers. When the group was asked about gender differences in math, James replied that he did notice a difference by reporting that boys do not really care about their grades and that girls care more. He stated:

In my experience, most of the boys don't really care about their grades. So they think, 'Oh, it doesn't matter if I get this wrong.' And on the other hand, in my experience, girls care more.

The female students in the focus group did appear to care very much about getting called on, participation, and completing classwork and homework. Jane reported differences as well, she stated:

Um, I mean it's really different. I mean we're all human beings and whenever, like, we like learn in school, we're all learning the same thing. But it probably is a little different because probably you know boys, you know they're different from girls of course, so like maybe some boys just don't pay attention in class, 
and maybe some girls, you know don't, and maybe the boys do. I just think that some things are different, and some things aren't.

Amelia answered:

Because it's like say, a boy is stronger than a girl. A girl can be stronger than a boy, because girls can, and like people always say boys always can be stronger but girls can also be stronger too. Let's say there's like mostly boys that are like, like smart sometimes, but girls can be too, you know, cause it's like saying...like, saying I'm really weak...and people are saying like....a boy's stronger... but you never know, maybe I could be stronger than the boy, you know, or we could both be strong.

Both Jane and Amelia's responses reference differences regarding gender.

Amelia gave an example of a common difference in physical strength between male and females in which she eventually explains that both males and females

can be strong. Similarly, Sarah responded:

I think it's kind of the same. But today, um, there was this group of people, like these three boys, and all of the questions, I was raising my hand, and she kept picking on those three boys, which was a little annoying. And I raised my hand um, three times, and I only got picked once. So then I just stopped raising my hand.

All students in the focus groups gave varying examples of differences by gender in the 
mathematics classroom.

As indicated in Table 4, throughout the focus group interviews, male students led the conversations and female students would respond afterwards. Sometimes female students would agree with their male counterparts, and continue the same conversation theme. Other times, female students and male students would add different insights to question responses. As indicated by the table, male students controlled the conversations. 
Table 4

Focus Groups Interviews: Conversation Response Types

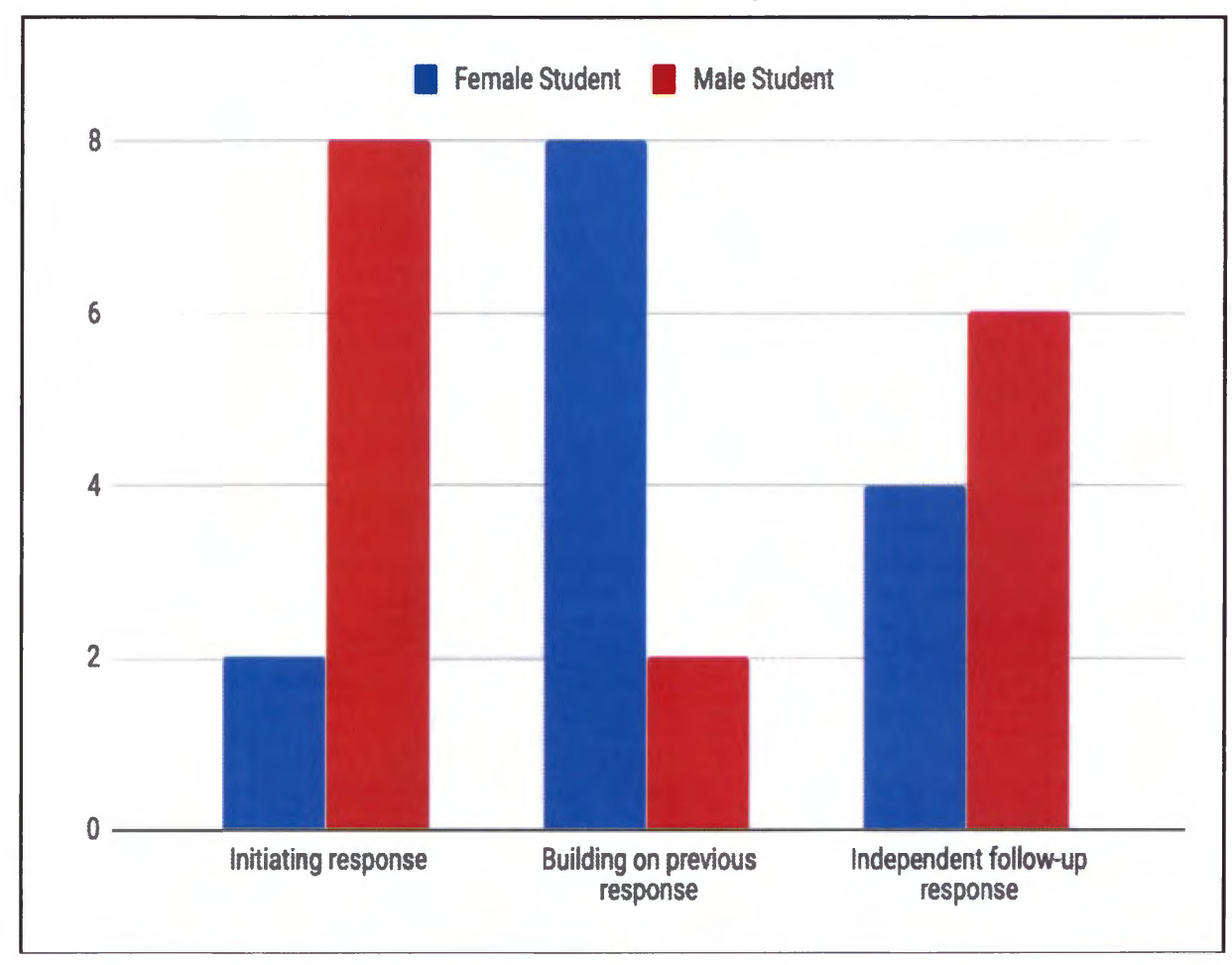

\section{Focus Group Two: Discussion of Math Teaching Video}

In the second round of focus group interviews, students watched a video and gave their observations. The video was from The Teaching Channel (The Teaching Channel, 2017). It showed a fifth grade class learning about geometrical attributes of different objects. The video was chosen with the requirement that it be the same grade level to the grade level of the research subjects who were in fifth grade, and included content they would be familiar with. The video tried to use engaging and current instructional practices. Students in the video led the conversation about the differences they noticed 
regarding the attributes of the geometrical shapes. The students were seated as an audience in front of the whiteboard, as opposed to traditional rows or table groups. I did notice that male students participated more and wondered, at the time, if the students during the focus group interviews would notice the same as well. Participant responses to the video revealed the theme of active teaching. Participants reported the teacher should help the students by explaining, teaching, asking, and showing students how to understand the learning objectives. 
Table 5

Focus Group With Video: Participant Response Codes by Gender

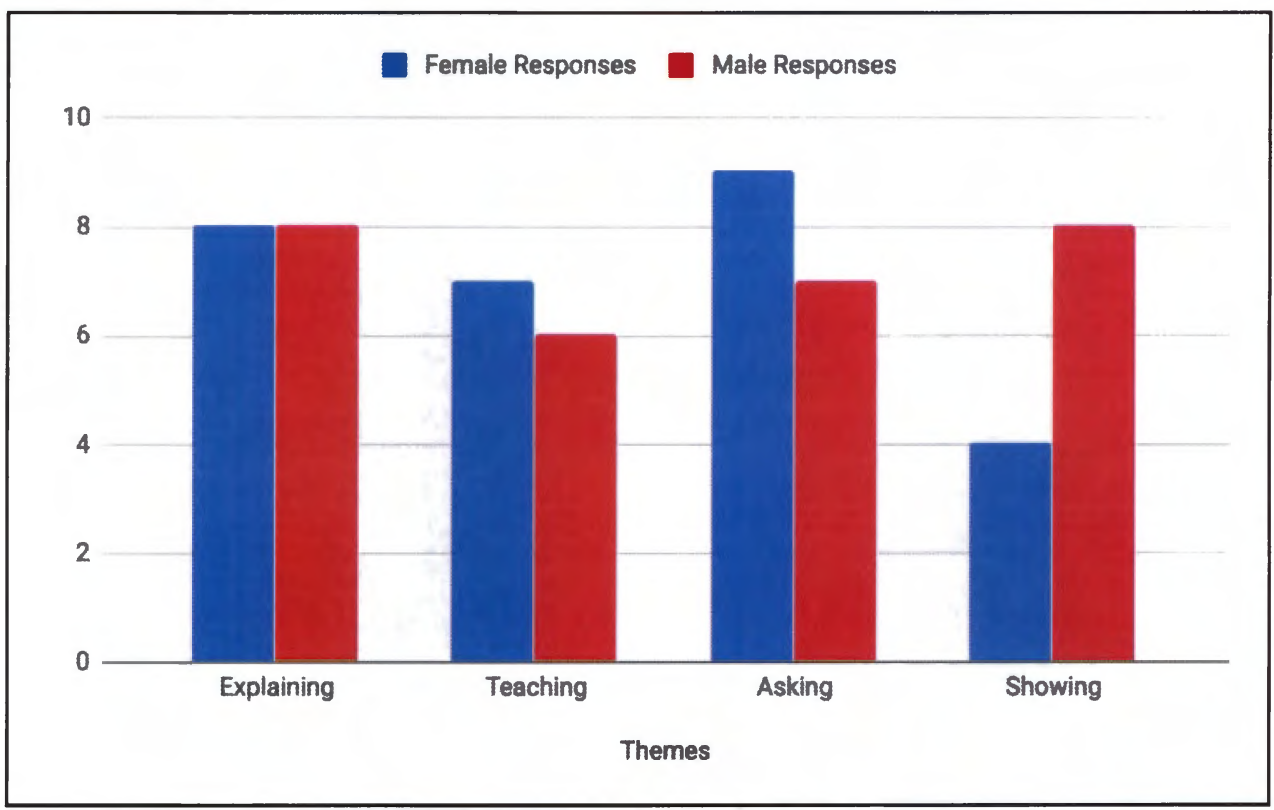

Overall, female and male students identified similar themes. The themes of explaining, teaching, asking, and showing came up multiple times across genders.

Stacy's comment captured both active themes of explaining and teaching. Stacy said:

The teacher should have them write it [the answer] down on a piece of paper because one person could go the whole day without answering anything or saying anything, and the teacher wouldn't notice. So that person could go a whole day without learning anything while everybody else is raising their hand and thinking about the question.

Stacy's commentary highlighted the participants' request for students in the video to have active opportunities to explain their thinking. 
Analysis of video for gender differences. Focus group participants reported that they noticed that most girls did not raise their hands. Students said they would like the teacher in the video to work on getting the girls to raise their hands more and pick on girls more frequently. Amelia addressed the differences in gender as related to classroom experiences by suggesting the teacher could say she was going to pick three girls and then three boys so that the opportunity for participation could be equal. Amelia suggested:

"I think teachers should instead of having people raise their hands, they can say, 'I'm going to pick on three boys and then I'm going to pick on three girls,' so then it can be equal."

Sarah suggested:

"I would say that the teacher should have time to pick on all the girls instead of just one."

Bree commented:

"I noticed in this video because I was counting with my hands how many boys she picked on and how many girls she picked on, and I noticed that she picked six boys, but she only picked three girls, so I feel like teachers sometimes pick more boys than they do girls. So I think they should pick equally, like, 'Oh, I already picked a boy. Let's pick a girl now."” 
The students agreed with each other that they would like to see equitable participation amongst genders during classroom instructional time.

Based on participation, students observed that girls and boys in the video did not have the same experience. Amelia also explained memories of times in the math classroom over the years when the teacher would call on male students intentionally for not paying attention. She commented that she felt that that held up the class from making progress learning new things. She stated, "There was like this kid that really didn't like pay attention a lot and the teacher would always call on him."

\section{Individual Interviews Analysis}

Individual student interviews were analyzed through the development of a code book. Words and phrases were coded as themes according to response type. Responses were recorded as generally positive or generally negative by gender. Additional themes arose including personal factors such as effort and ability. Many students mentioned the idea of mathematical content as well. 
Table 6

Individual Interviews: Participant Response Codes by Gender

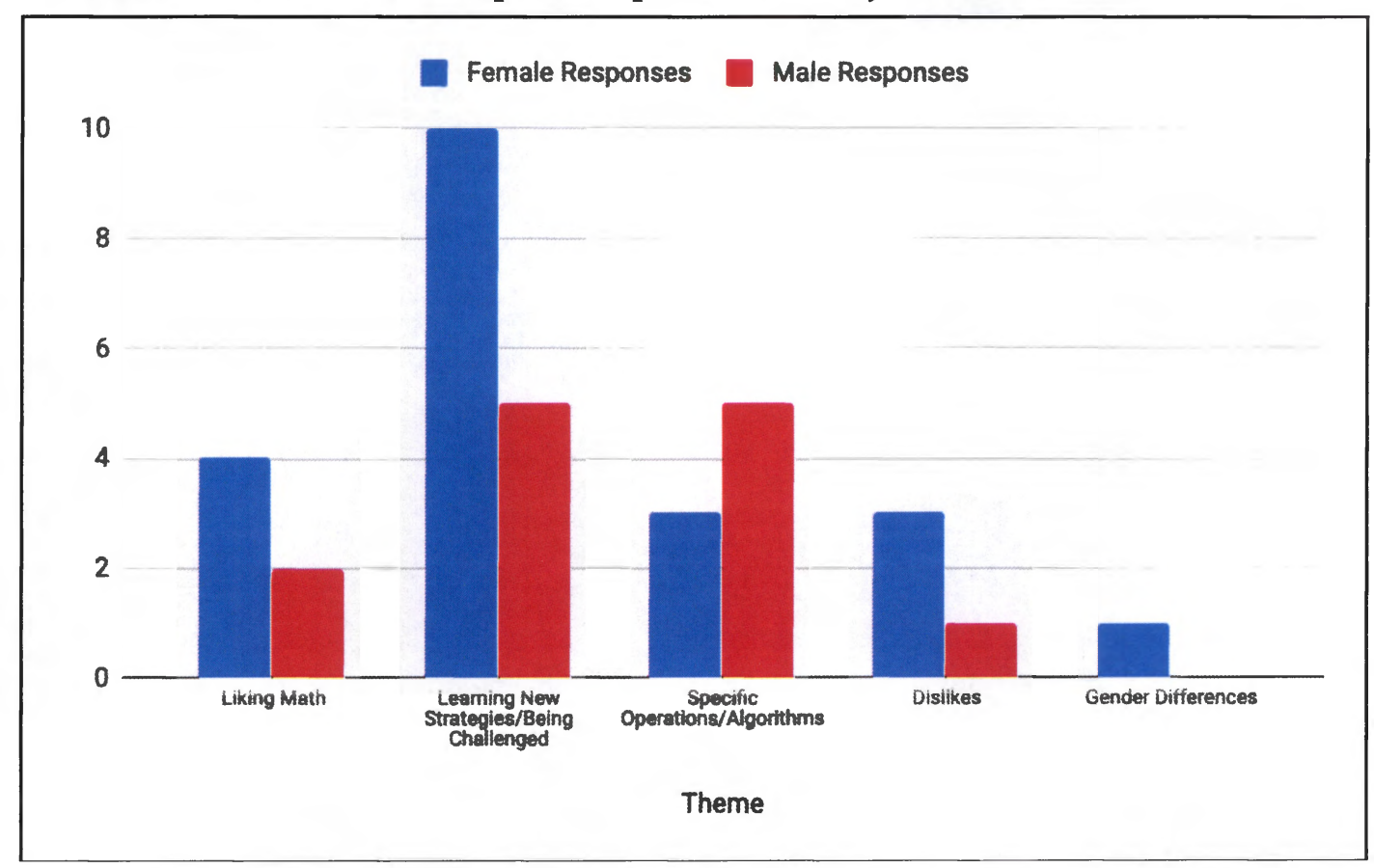

At the start of the interview, students were asked to base their responses on their overall experiences in mathematics both at home and at school, from as young as they could remember. Their answers were based off of their collective experiences in mathematics.

Female students expressed an overall positive response regarding their general thoughts on learning math. Words such as, "like," "love," "fun," and "great" were used repeatedly to explain math learning in general terms. Male students expressed an overall positive response in regard to their general thoughts on learning math, however, different words were used. Male students used words such as, "focus" and "practice." 
Another difference between the female and male responses were that male students referenced real world applications such as using math to budget for buying food and future jobs, whereas female students referenced more of the day to day experiences in math such as working with partners or in small groups, and understanding and learning new concepts adequately.

There was a certain type of nuance in the words chosen by female and male students to describe math. The nuance present within the types of adjectives that were used by gender was interesting and surprising. The adjectives that female students used to describe math were simplified and general. The adjectives that male students used to describe math were direct and outcome oriented. It was shocking that as early as fifth grade male students described math in a more nuanced way than the female students.

When asked what they liked about math, both female and male students referred heavily to mathematical content such as basic operations and the use of strategies such as number lines and arrays to solve problems. Jane said, "When I grow up, I can know more things than I know now and use them in life and stuff." Both groups expressed a positive response to getting the correct answer. When asked what they disliked about math, the majority of male students responded that they disliked nothing. This was a reversal of the written responses, in which male students had an overall more negative than positive tone. 
Female students also spoke mostly positively about math content but mentioned three things they disliked about math. The three things they mentioned were: rounding, division because of remainders, and having math in the morning. Michael was the only male student who offered a dislike of mathematics. He said he disliked having to do something that is timed.

In terms of learning math, female students named personal factors that related to effort. Female students repeatedly said they learn math from, "being challenged," and "not learning the same thing for three weeks." Male students named personal factors that related to ability. Male students said the best ways they learn math include the following: paying attention, getting the answer, using the details, the traditional regular way, memorizing, taking notes, and working one on one. When compared to the female students' responses, the male students' responses were more specific in regard to the ways in which they feel successful in learning math.

When asked whether or not they thought it was the same or different being a boy or girl in math, all students, with the exception of one female student reported no differences. Amelia said:

"Sometimes it can be the same. It depends on what teacher you get. The teacher calls on boys more than girls."

When asked if there was any additional information she would like to add, Amelia 
replied:

"Challenge me more. Try to do stuff that's a little harder. Call on girls and boys."

Bree also responded:

"Challenge me more with harder questions."

These were the two female students who also expressed that they learn math best when they are "challenged more." When asked to offer additional insights and information, male students listed factors attributed to personal ability. They mentioned things such as showing your work, trying your best, answering their questions, focusing, and memorizing.

\section{Formal Mathematics Assessment Data}

Two sets of student assessment data were analyzed. The first student assessment data were student math scores on the California Assessment of Student Performance and Progress (CAASPP) from May 2018. One female student exceeded standards, while no male students exceeded standards. Three female students met standards, six male students met standards. Four female students nearly met standards. Three male students nearly met standards. There were no students among the research participants who did not meet standards. 
The second set of data analyzed were the Unit One Bridges assessments. The assessment was from the school's mathematics curriculum and included mathematics and division concepts as related to volume. All students completed the nine-question assessment in October of 2018. The Unit One assessment was worth thirty-five points. Five female students scored seventy percent or higher and four male students scored seventy percent or higher. Three female students scored below seventy percent and five male students scored below seventy percent.

The assessment data further supports the primary source data from Chapter One. In fifth grade, there is not evidence of a male/female achievement gap. The groups demonstrated the same percentages of achievement on two data measures, and the standardized achievement scores roughly correlated to scores on the curriculum-based assessment. Thus, while there are clear differences in how the girls described their experiences in math, this does not yet show up either positively or negatively in terms of their achievement. 
Table 7

Female Student Achievement Data

\begin{tabular}{|l|l|l|l|}
\hline Female Student & Race/Language & Bridges & CAASPP \\
\hline 1. Liz & Caucasian & $89 \%$ & $\begin{array}{l}\text { Standard } \\
\text { Exceeded }\end{array}$ \\
\hline 2. Bree & Latinx & $86 \%$ & Standard Met \\
\hline 3. Sarah & Latinx & $89 \%$ & Standard Met \\
\hline 4. Stacy & Latinx & $71 \%$ & Standard Met \\
\hline 5. Jill & Latinx/EL & $74 \%$ & $\begin{array}{l}\text { Standard } \\
\text { Nearly Met }\end{array}$ \\
\hline 6. Amelia & Latinx & $60 \%$ & $\begin{array}{l}\text { Standard } \\
\text { Nearly Met }\end{array}$ \\
\hline 7. Jane & Latinx & $46 \%$ & $\begin{array}{l}\text { Standard } \\
\text { Nearly Met }\end{array}$ \\
\hline 8. Patty & Latinx/EL & $37 \%$ & $\begin{array}{l}\text { Standard } \\
\text { Nearly Met }\end{array}$ \\
\hline
\end{tabular}


Table 8

Male Student Achievement Data

\begin{tabular}{|l|l|l|l|}
\hline Male Student & Race/Language & Bridges & CAASPP \\
\hline 1. Sean & Latinx & $86 \%$ & Standard Met \\
\hline 2. Jack & Latinx & $85 \%$ & Standard Met \\
\hline 3. Michael & Latinx & $86 \%$ & Standard Met \\
\hline 4. John & Latinx & $80 \%$ & Standard Met \\
\hline 5. Jake & Latinx & $69 \%$ & Standard Met \\
\hline 6. James & Not reported & $52 \%$ & Standard Met \\
\hline 7. Jose & Latinx & $45 \%$ & $\begin{array}{l}\text { Standard } \\
\text { Nearly Met }\end{array}$ \\
\hline 8. Seth & Latinx/EL & $49 \%$ & $\begin{array}{l}\text { Standard } \\
\text { Nearly Met }\end{array}$ \\
\hline 9. Conor & Latinx/EL & $29 \%$ & $\begin{array}{l}\text { Standard } \\
\text { Nearly Met }\end{array}$ \\
\hline
\end{tabular}

\section{Observations of Focal Students and Case Study}

Classroom observations were centered on focal students. The focal students, Jane and Amelia, emerged through the analysis of writing samples, focus groups, and individual interviews. The focal students were chosen because their responses, both verbal and written, represent inspired and encouraged learners, who hold high selfexpectations and demonstrate a desire to achieve. Jane and Amelia emerged as students who displayed generally positive attitudes towards mathematics. Both students were ten 
year old Latinx students who have attended Oak Elementary School since Kindergarten.

The students attend a school in which $83 \%$ of the children are socio-economically disadvantaged, $47 \%$ are English Language Learners, and $72 \%$ of students are Latinx.

Jane had previously explained her frustration with mathematics in regard to not always getting called on when she raised her hand. Both students had expressed nuanced gender differences between male and female classroom experiences, and both advocated for male and female students to be treated the same. Jane and Amelia expressed a strong desire to be challenged more in the classroom.

However, what was surprising to me about both Jane and Amelia was that I expected their assessment data to meet or exceed standards for CAASPP, as well as score above $70 \%$ on the Bridges Unit One assessment. Jane and Amelia both scored, "Standard Nearly Met" on CAASPP. Amelia's Unit One assessment score was 60\%. Jane's Unit

One assessment score was $46 \%$. The ways in which both Jane and Amelia spoke about math was positive, confident, and hopeful.

\section{Student Perceptions of Classroom Management}

The fifth grade classrooms participated in timed math facts tests. Students were typically called on via their name written on a stick being pulled out of a jar. Classroom observations revealed the daily routine in mathematics consisted of completing an interactive homework review while sitting at table groups with four or five students, and 
talking to a partner about their homework responses. Next, the classes would gather on the carpet to learn a new concept, which also involved talking to a partner.

The lessons typically progressed with the whole class grouped on the carpet. During a specific day of whole group instruction manipulating fractions Jane commented, "I did ten times four, because the first step is multiply the denominator with the whole. Then I did forty plus one." The teacher asked, "Where did the one come from?" Jane responded, "It's the numerator and the denominator stayed the same." Jane was able to explain her thinking as it pertained to manipulating fractions greater than one to the class.

When the students returned to their table groups to work independently on the new concept, Jane and Amelia had the following interaction with their table group. Jane said to Conor, "This is so easy." Amelia said, "It's so easy when you do all the steps." Conor and James did not respond. This interaction was representative of high levels of confidence as demonstrated by both Jane and Amelia.

During one classroom observation, Jane engaged in a discussion with the teacher in which she pointed out that she thought her stick with her name on it was missing from the stick jar. After an inspection of the jar, the teacher realized this was the case and added a stick with Jane's name on it to the jar. Oddly enough, throughout the interviews, Jane would often comment about a discrepancy she had noticed with not being called on. 
What stood out to me specifically about Amelia and Jane was that their discourse in the classroom at their small table setting and during the whole group instruction was observed to be very active and highly participatory levels of verbal and written discourses with each other. At the same time it was observed that male students sat back, passively at their tables, and were basically agreeable and not interactive with the female students. The female students were excited about what they were learning. The male students were observed to be passive, but agreeable, and not highly participatory in the small group setting. This is directly in conflict with the positioning that happened in the focal group interviews in which male students often started the conversation and female students were agreeable to their input.

Understanding students' hope and confidence. As a result of the data analysis, two female students stood out because of their ability to think critically about their experiences in math. Both Amelia and Jane called out instructional practices in regard to gender that could have a potentially negative impact on the development of positive mathematical identities. Both Jane and Amelia were Latinx students who, according to assessment data were nearly meeting standards. This was surprising, because throughout the writing prompt and interviews, their voices were filled with strength and optimism. When asked if there was anything teachers should know about teaching girls, specifically in math, Amelia replied: 
Well, I think that since women didn't have equal rights back then, if girls didn't understand (math), maybe they (teachers) should just help them a little more. Maybe it's our time now. I think that women just need to have their time now, right now. So I think that the girls, they're smart and so are boys. And I don't really think that you should change anything because of girls. They are very smart. So are boys, but women create life on this world, so, I think that women should just have their time now.

I was moved by the level of confidence, courage, perseverance and hope in Amelia's voice. She spoke in a way that transcended mathematics as a core classroom subject and brought up issues of women's rights over history. She made the above mentioned statement at the end of our one on one interview when I asked if there was anything else she would like to add.

To hear the hopefulness, potential and perseverance in Amelia's voice, at just ten years old, on a random math interview with the principal of the school and for her to say all of that, was really a tribute to her positionally as a ten year old Latinx female student. I found it to be quite moving and a powerful example of student voice.

A quote that reflects Jane's confidence was evidenced from the following excerpt from a focus group interview. Jane stated:

I love getting challenged. Let's say we had a really, really hard equation. I like 
getting challenged to see if I got it right or wrong. And I also like to know...let's say we have a really, really hard math problem, I like to solve it by myself and see if I got it right or wrong and I learn from my mistakes.

Jane expressed self-confidence through learning from her mistakes to get the right answer. Her insights are directly related to success in mathematics.

Both Amelia and Jane's interactions with each other during the classroom observations were representative of confidence and positive attitudes towards math. They both demonstrated high levels of participation, work completion and positivity. However, both girls pointed out discrepancies in experiences in the math classroom as related to their male counterparts.

The role of gender as described by focal students. Jane and Amelia picked up on subtleties in gender and how that related to the socialization structures that both male and female students encounter throughout their life experiences. The subtleties that I noticed between genders was a surprise, because I did not think it existed at ten years old. The female students talked about mathematics in terms of classroom application and wanting to be successful in the classroom. Female students did not generalize mathematics beyond successes outside of the classroom. Female students reported that they want people to have high expectation of them, specifically adults. They advocated for participation equity. They are bothered when they do not get called on, or are 
overlooked in participation.

\section{Summary and Synthesis}

The main themes that emerged from the data are those of being challenged, learning new concepts and strategies, gender equity participation, support from the teacher, and home experiences. While achievement data showed little difference between female and male achievement, girls reported a different experience in the math classroom. Both boys and girls were readily able to identify and discuss gender differences that impacted their math classroom experiences, with all agreeing that boys were called on more and "took up more space" in classroom discourse.

Despite these disparities, the girls in the study exhibited largely positive attitudes towards math and want to be fully included in math discourse. In Chapter Five, I will discuss ways in which teachers, site level leaders, and policy makers can use these findings to support the development of positive mathematical identities in female students. 


\section{Chapter 5: Discussion and Recommendations}

This study investigated the ways in which female students experienced mathematics, and how that supported a positive attitude towards mathematics. The research was conducted at a diverse elementary school in Northern California.

Specifically, the study addressed the following research question: "How do instructional practices that fifth grade female students experience at school support and relate to the development of positive mathematical attitudes?"

To answer the question, the study employed a qualitative research design to analyze students' responses regarding their experiences in mathematics thus far. To further inform the research, the design also included classroom observations and student assessment data.

\section{Key Findings}

Female students want to be called on, literally. They want their voices to be heard. Successful learning experiences in the classroom such as being challenged and getting the right answer help contribute to the development of positive mathematical attitudes.

If female students express a desire to learn math in a challenging way, let us honor that and have high expectations. The data tells an important story. Overall, there 
is a positive iteration of female experiences in the math classroom, clouded by a negative one. The positive iteration comes from females reporting, at high levels, a willingness to learn and be active participants in the math classroom. The negative iteration comes from male students confirming different experiences in the classroom in which they selfreport being less engaged, but receiving more attention.

Based on what female students reported, there is a complex relationship between student perceived reality in the mathematics classroom and actual classroom reality. Female students are aware of subtleties and nuances that the teacher may or may not be aware of. This has developed over previous years of schooling. Female students can develop positive attitudes towards mathematics when the following are in place: high expectations from teachers and guardians, participation equity in the classroom, a homeschool connection that supports engaging and fun math experiences at home and at school, and a hyper-awareness from adults regarding implicit and explicit gender bias. Findings from the research question revealed evidence that male and female students have different experiences in the classroom in terms of who gets called on. Female students reported that their male counterparts get called on more frequently as a way for teachers to make sure that they are paying attention. A recurring pattern of responses in focus group and individual interviews revealed that both male and female students experienced and observed this in their educational experiences. Regardless of 
negative experiences with support from home, as well as classroom experiences where their voices are overshadowed by male students, female students remain positive towards mathematics. The female students in this study have generally positive attitudes towards math.

\section{Evidence in Relation to Research Question}

Based on their responses to interview questions and the writing prompt, female students currently have positive mathematical identities. There is evidence that suggests there are specific ways to support the development of positive mathematical identities in female students.

First, ensure participation equity as it relates to gender takes place in the classroom. A supportive practice is to intentionally ensure that equal amounts of female and male students participate in the classroom. This could include strategies such as keeping track of how many girls and boys are called on during a math lesson, so that equal amounts of individual verbal participation regularly take place in the classroom.

Specifically, teachers need to be hyper aware of who is participating and in what ways. Second, make sure that female students are challenged in their math learning. In both written responses and throughout the interviews, female students requested to be 
challenged in math. A supportive practice is ensuring high levels of differentiation through the intentional incorporation of high cognitive demand tasks. Using formative math tasks to guide instruction in addition to engaging teaching strategies such as feedback and revision and re-engagement will support this request.

Third, develop positive relationships with families to discuss the importance of enacting positive math discourse at home. Male students reported fun and engaging experiences at home such as playing games and positive discussions with family members about mathematics. However, this was not the case for female students. A supportive practice is to develop positive home/school connection that provides ideas for math positivity at home. A suggestion is to approach math in a fun and engaging way. An example is estimate the total cost of the shopping bill and compare it to the final bill. Lastly, have high expectations for female students in mathematics. Female students want to be challenged and engaged in the mathematics classroom. A recurring theme that female students brought up was teachers' giving extra attention to male students who were not paying attention. A supportive practice is using the students who are engaged as role models for the rest of the class. All of these practices are supported by the data. 


\section{Relationship of Findings to Existing Literature}

The findings expand on, coincide with, and support the existing literature.

Female students want teachers to have high expectations of them. Instructional decisions made by teachers, such as giving female students the opportunity to be active problem solvers, allowing for high cognitive demand tasks, the use of open-ended questions and discussions, as well as student led discussions support the need for teachers to have high expectations of female students in the mathematics classroom (Willingham, 2009;

Larnell, 2016; Martin et al., 2015). Female students will benefit from engaging in challenging math tasks.

Having high expectations for female students corresponds to the work of Joseph, Hailu and Boston (2017) because female students benefit from solving grand challenges in mathematics. Positive teacher mindset (Wickstrom, 2015; Cobb \& Jackson, 2013) towards students' capabilities also supports the finding that female student benefit from high expectations.

Creating a positive home to school and school to home math connection corresponds to the work of Langer-Osuna and Nasir (2016), Esmonde and Langer-Osuna (2013) as mathematical identity is tied to students' home cultures. The home to school 
and school to home connection also corresponds to culturally relevant pedagogy as connecting mathematics instruction to students' lived experiences (Ramsay-Jordan, 2017; Aguirre \& Zavala, 2013). The research of Martin et al. (2015) also supports the recommendation that the type of tasks students engage in, such as games, can increase their mathematical thinking. Students can play mathematical games at home to increase and support a positive home to school connection with mathematics.

Participation equity corresponds to the literature in indirect ways. Teachers' mindsets towards how female and male students participate in the classroom can ensure participation equity (Jackson, 2013). When teachers are aware of who is participating, how frequently they are participating, and the ways in which they are participating, participation equity as it relates to gender can be ensured. In terms of teacher mindset, teachers should be aware of their mindsets towards participation in terms of who is participating and in what ways.

This work expanded the existing literature by including student voice. The findings support the existing literature by further adding to the complex relationship of teaching and learning as it relates to teacher and student mindsets. The research supports Wickstrom (2015) and Cobb and Jackson's (2013) ideas of the need to create and support 
meaningful learning opportunities for students in which the students position themselves as mathematically capable, confident and proficient. Positive mindsets support positive learning outcomes and positive attitudes towards math.

Pedagogy, or instructional practices, play a role in developing positive mathematical attitudes for female students. Female students reported wanting to take an active role in what they experienced with instructional practices when they requested more challenging mathematical learning and experiences. The findings of this study support the literature in pedagogy because female students need the opportunities to participate in mathematics learning that includes high cognitive demand tasks such as open ended discussions, high-level questions, and math instruction that balances procedural and conceptual math (Martin et al., 2015). In terms of culturally relevant pedagogy, mathematics instruction should value students' lived experiences. This is directly related to students' experiences at home in regard to the role of math at home. This also corresponds to the work of Ukpokodu (2011) in which mathematics framed as being unique each culture. Space needs to be made within mathematics classrooms for this to take place.

This study suggests that female student mindsets towards mathematics are 
generally positive. The female students who participated in this study view themselves as confident doers of mathematics. Female students did report inequitable opportunities for discourse, in terms of who is consistently called on to verbally participate in the mathematics classroom. Mindset shapes identity and attitude. Female students who participated in this study report positive mathematical identities and attitudes towards math. This is evidence of a school culture that values and corresponds to the students' own cultures (Tichenor et al., 2016).

Most importantly, this study revealed that gender does play a role in the elementary mathematics classroom. Female students are marginalized as it corresponds to their opportunities to participate in discourse. This relates to a difference in how genders are engaged in the classroom (Aragon et al., 2018; Reinholz and Shah, 2018; Rimm-Kaufmann et al., 2015). Both female and male students reported different experiences related to gender in mathematics.

\section{Limitations of the Research}

Limitations of this study primarily existed regarding the sample size and selection of research participants. The sample size was small due to having limited access to one elementary school. The selection of students was limited to fifth grade students, a vulnerable population. My own positionality was a limitation as well. Being the principal of the elementary school where the research was conducted had an effect on the 
outcomes. Time was a limitation. I had one semester to collect the data, which was the equivalent of a few months. Similarly, lack of time impacted the analysis of the data, as I had a few months to complete that task as well.

Alternatives to avoid and address these limitations in future studies can support findings. An outside researcher who does not work at the school in which the subjects attend would support unbiased interactions with the research subjects. A larger study with an increased number of participants would add data and information to future studies, as well as provide additional and possibly more diverse findings. A study with broader reach that included students from more than one elementary school would support additional research.

The period of time over which the data was collected is also a limitation. The data collection time frame was only two months. This limits the research because due to the lack of time, there was no sense of how female attitudes towards math may change over time. There is no data over time of how student assessment data may change. The data collection period ended prior to the Spring when students would take the California Assessment of Student Performance and Progress again (CAASPP). Additionally, all other curricular unit assessments throughout the school year could be included if the data collection period were longer. Only procedural mathematics was observed during the 
division unit that was being taught. I was limited by seeing only students' learning experiences to the math unit observed, which was solely procedural mathematics instruction. The short period of time for data collection, in addition to not being able to observe any academic or attitudinal changes over time towards mathematics are limitations of this research.

\section{Implications for Practice}

There are implications for specific areas of practice as a direct result from the outcomes of this study. Classroom instruction, school leadership, and school policy can be directly influenced by this work.

\section{Recommendations for Classroom Instruction}

Female students expect others to have high expectations for them in the mathematics classroom. Female students want to be challenged in mathematics.

School leaders need to develop specific ways to support the home school connection so that female students have positive experiences related to mathematics at home. For example, playing games that involve mathematics and talking about mathematics in positive ways will support the development of positive female attitudes in mathematics. Our collective responsibility is to ensure student success for all students. Male students have a certain level of entitlement that shows up as passivity.

The implications of this study are for educators to have high expectations for 
female students in mathematics, and to be aware of participation equity in terms of who is participating. It is important for educators to be aware of the ways in which students participate that are specific to the learning environment and activity. Be aware of the home and school connection between mathematics, and specific ways in which we can enlist parents to have positive interactions at home with their daughters. Be aware of your own gender bias and the role that plays in how you treat female and male students.

\section{Recommendations for School Leadership}

It is important for school leaders to provide the necessary spaced needed for teachers to examine their own practice as it relates to who is called on in during mathematics instructional time. It is recommended that school leaders provide teachers with tools, as simple as a tally chart, to be able to track who is getting called on and who is speaking in the math classrooms. Additionally, school leaders should allow time for teachers to discuss and analyze this data. Then, make next steps to address gender equity participation to ensure that it takes place. School leaders should take time to connect with students to ask them about their learning experiences in math.

Teachers will benefit from opportunities to discuss their own mathematical identities and attitudes towards math. It is critical for school leaders to give teachers opportunities to develop positive attitudes towards mathematics in trusting professional settings. This can be done at staff meetings and district-wide meetings. Adults benefit 
from opportunities of doing math and talking about math. This will increase their

confidence in successfully teaching mathematics.

\section{Recommendations for Budget and Policy}

The ways in which districts decide to allocate monies towards the teaching and learning of mathematics, in turn, supports student success. While effective and engaging instruction, as well as a curriculum that has high cognitive demand, monies directed towards supporting mathematics learning can have a potentially positive impact on student success. Budgetary expenditures in the Local Control Funding Formula (LCFF) are aligned to schools' Local Control Accountability Plans (LCAPs). The expenditures in mathematics need to be done in a way that is specifically tied to student success while demonstrating a high level of accountability.

Increasing spending in mathematics is a starting point of how improvement can begin to take place. Not only is not enough money spent on math education, the ways in which the typically small amounts of monies are budgeted are vague and not related to specific goals centered around student success. The obvious solution to this problem is to increase the amount of money spent in district LCAPs on mathematics.

One of the main issues that could function as a barrier towards making the case

for more money to be put towards mathematics is that people tend to have fixed mindsets, stereotypes, and negative attitudes about mathematics. However, the teaching and 
learning of mathematics is also high stakes because of student test scores and achievement gaps that exist within student performance. Unlike me, math is not everyone's most favorite thing in the world. Often times, people have had a negative experience learning math and/or teaching math. Thus their mathematical identities and narratives are established with a negative perspective and further perpetuate a deficit and fixed mindset towards students and students' abilities in mathematics.

Advocating to the superintendent, board members, staff, and school communities to increase math spending is a necessary and needed change. Enlisting others to see the need for additional monies to support mathematics within district budgets serves as an additional solution. Often, the decision to allocate more money to math instruction is one that cannot be made unilaterally. Superintendents, board members, teachers, and school communities need to be convinced that this is a necessary and needed change.

\section{Recommendations for Future Research}

Future research needs to continue to be conducted that includes the voices of elementary age children. Student voice needs to be the focal point of the research. This research has demonstrated that including student voice is a critical component to ensuring equitable outcomes for students. Researchers, teachers, school leaders, and policy makers have much to gain and learn from the insights of children. It is important to include their voices because children have valuable insights to add. 
The same research, but on a larger scale, conducted with a larger population would add valuable information to this study. Additional research needs to be conducted at the elementary level that focuses on student voice and the ways in which the students report learning math as being the most successful. This approach supports education as a vehicle to enact change and disrupt hegemonic normative systems in place.

\section{Conclusion}

Female students need to receive specific and continuous support in mathematics when compared to their male counterparts. This support will ensure the development of positive mathematical identities as it relates to positive attitudes towards mathematics, that is specific to female students. A positive mathematical identity can open doors for female students in the classroom and beyond.

I have related to this work because of my positionality as a female math researcher. Changing the mathematical mindsets of adults is the main reason why I was hired in my last two positions as an elementary school principal. I am where I am because of the role that math has played in my life. It could be said that it was purely by luck and chance that I have developed a positive math identity. At least, my math identity was shaped after I became a teacher, as I do not have any positive or negative memories of mathematics from my elementary and secondary education experiences. My positive mathematical identity is why I am a current principal of five years and past 
teacher of eleven years. Math became my favorite subject to teach. Math is my favorite topic to discuss.

It is fitting that this work end with a quote from Amelia, "There's basically math, like everywhere, if you go notice it. 
Appendix A

\section{San Francisco State University \\ Parental Permission for a Minor to Participate in Research \\ A Study: Mathematical Discourse and $5^{\text {th }}$ Grade Female Students}

\section{A. PURPOSE AND BACKGROUND}

My name is Mary Reynolds. I am a graduate student at San Francisco State University in the Educational Leadership doctoral program, and I am conducting research about how students develop a positive mathematical identity. I am inviting your child to take part in the research because her insights would help teachers and educational leaders with the teaching of mathematics.

\section{B. PROCEDURES}

If you agree to let your child participate in this research, the following will occur:

- Your child will be asked to write about how they learn math, participate in a focus group, classroom observation, and interview.

- This will take place in their regular classroom as part of the scheduled curriculum.

- Your child will participate in a group discussion in math class about how they best learn math. The discussions will be audio recorded.

- Data will be collected during the regular school day throughout August 2018-October 2018.

- The time of the regular school day is $8: 20 \mathrm{am}-2: 39 \mathrm{pm}$.

- Students will participate in group interviews and focus groups with the researcher during part of their school day that has the least amount of impact on their day.

- Student work and research will be completed within the hours of the regular school day between 8:20am-2:39pm.

- The research will take place at Oak Elementary Charter School, in California.

- Focus groups and group interviews will last no longer than one twentyminute session per school day. Student work will be completed within the regular school day during math instructional time. The total time commitment per participant will not exceed ninety minutes.

- Your child will not miss class.

- The researcher, Mary Reynolds and, at times, your child's teacher will be present in the room with your child. 


\section{RISKS}

There is a risk of loss of privacy, which the researcher will reduce by not using any real names or other identifiers in the written report. The researcher will also keep all data in a locked file cabinet in a secure location. Only the researcher will have access to the data. At the end of the study, data will be shredded.

There may be some discomfort at being asked some of the questions. Your child may answer only those questions he or she wants to, or your child may stop the entire process at any time, without penalty to them.

\section{CONFIDENTIALITY}

The research data will be kept in a secure location in the researcher's office. The data will be kept for three years, after which time, the data will be destroyed. Only the researcher will have access to the data. At the conclusion of the study, all identifying information will be removed and the data will be kept in a locked cabinet or office. Audio or video recordings will be destroyed at the end of the study.

\section{E. DIRECT BENEFITS}

There are no direct benefits for your child's participation in this project.

\section{F. COSTS}

There will be no costs for your child's participation in this project.

\section{G. COMPENSATION}

There will be no compensation for participation in this project.

\section{H. ALTERNATIVES}

The alternative is not to participate.

\section{QUESTIONS}

You have spoken with Mary Reynolds about this study and have had your questions answered. If you have any further questions about the study, you may contact the researcher by email at mreynolds@org, or you may contact Professor Stephanie SiskHilton by email at stephsh@sfsu.edu. Questions about your child's rights as a study participant, or comments or complaints about the study also may be addressed to Human and Animal Protections at San Francisco State University, at 415-338-1093 or protocol@sfsu.edu.

\section{J. CONSENT}

You have been given a copy of this consent form to keep. PARTICIPATION IN THIS RESEARCH IS VOLUNTARY. You are free to decline to have your child participate in this research. You may withdraw your child's participation at any point without penalty. 
Your decision whether or not to participate in this research will have no influence on your or your child's present or future status at Oak Elementary Charter School.

Child's Name

Signature

Parent/Guardian

Signature

Researcher
Date:

Date: 


\title{
Minor Assent Form \\ 9 to 13 year olds (grades 4 through 8 )
}

\author{
San Francisco State University \\ Agreement to Be Part of a Research Study
}

Dear $5^{\text {th }}$ Grade Students,

In addition to being your principal, I am also studying for my doctoral degree in Educational Leadership at San Francisco State University. I'm writing a paper about how students learn math as a project for my school.

As part of your regular math class, you will have the opportunity to talk to me about how you learn math and do math exercises on paper. I want to learn about how your experiences learning mathematics shape your experiences with math. I want my research to help me understand how you learn math in ways that establish a positive and successful learning opportunities for you and future students.

Your participation is voluntary. You don't have to participate. Your math grade will not be affected either way.

If you don't want to participate, just do not sign this form.

Thank you,

Ms. Reynolds

Researcher's signature

Date

Student's name

Date

Student's signature

Date 


\section{Appendix B}

\section{$\underline{\text { Student Writing Prompt }}$}

Directions: Spend no more than twenty minutes writing about one or more of the following prompts.

What are your thoughts about learning math?

What do you like about math?

Is there anything you dislike about math?

Please write any other thoughts you have about math in the space provided.

\section{$\underline{\text { Student Interview Questions }}$}

How do you best learn math?

What is a positive experience you have had with math?

What is a negative experience you have had with math?

What is your favorite thing about math?

What is your least favorite thing about math?

Do you think it's different or about the same being a boy or a girl in your math class?

Do you have any additional information or insights to share that you think would be helpful for teachers to best teach you math?

\section{Focus Group Questions}

Let's discuss the video with the following questions:

If you were in this classroom, what would help you learn math? 
If you were the teacher, what would you do? What would you tell the teacher about this class?

Is there anything teachers should know about teaching girls in math?

Do you think that girls and boys had the same experiences in that classroom? If not, how were their experiences different?

What other information could you give that would help the students in that classroom learn? 
References

Aguirre, J. M., \& Zavala, M. R. (2013). Making culturally responsive mathematics teaching explicit: a lesson analysis tool. Pedagogies: An International Journal, 8(2), 163-190.

Anderson, R. (2007). Being a Mathematics Learner: Four Faces of Identity. Mathematics Educator, 17(1), 7-14.

Aragón, E., Serrano, N., \& Navarro, J. I. (2018). Do Boys and Girls Learn the Same Way? A Preliminary Study in Primary Education Analyzing Gender Differences. Electronic Journal of Research in Educational Psychology, 16(46), 537-553.

Bachman, Heather J. (2015). Opportunities for Learning Math in Elementary School: Implications for SES Disparities in Procedural and Conceptual Math Skills. American Educational Research Journal., 52(5), 894-923.

Banse, H. W., Palacios, N. A., Merritt, E. G., \& Rimm-Kaufman, S. E. (2016). 5 strategies for scaffolding math discourse with ELLs. Teaching Children Mathematics, 23(2), 100-108. Retrieved from: http://www.jistor.org/stable/10.5951/teacchilmath.23.2.0100

Battey, D. (2013). "Good" mathematics teaching for students of color and those in poverty: The importance of relational interactions within instruction. Educational Studies in Mathematics, 82(1), 125-144.

Bieda, K. N., \& Lepak, J. (2014). Are you convinced? Middle-Grade students' evaluations of mathematical arguments. School Science and Mathematics, 114(4), 166-177. doi:10.1111/ssm.12066

California Assessment of Student Performance and Progress. (2016). Test results for English language arts/literacy and mathematics. Retrieved from: http://caaspp.cde.ca.gov/sb2015/ViewReport?ps=true\&lstTestYear=2015\&lstTest Type $=$

Charmaz, K. (2014). Constructing grounded theory. London: Sage Publications.

Cobb, P., \& Jackson, T. (2013). Lessons for mathematics education from the practices of African American mathematics teachers. Teachers College Record, 115(2), 114. 
Delpit, L. (2012). "Multiplication is for white people." Raising expectations for other people's children. New York: The New Press.

Dunleavy, T. K. (2015). Delegating mathematical authority as a means to strive toward equity. Journal of Urban Mathematics Education, 8(1), 62-82.

Dweck, C. S. (2006). Mindset: The new psychology of success. New York, NY, US: Random House.

Esmonde, I., \& Langer-Osuna, J. M. (2013). Power in numbers: Student participation in mathematical discussions in heterogeneous spaces. Journal For Research In Mathematics Education, 44(1), 288-315.

Goodlad, J. I. (1984). A place called school. New York: McGraw-Hill.

Gee, J. P. (2004). Discourse analysis: What makes it critical? In R. Rogers (Ed.), An introduction to critical discourse analysis in education. (pp. 19-50). Mahwah, NJ: L. Erlbaum Associates.

Jackson, C. (2013). Elementary mathematics teachers' knowledge of equity pedagogy. Current Issues in Education, 16(1). Retrieved from: http://cie.asu.edu/ois/index.php/cieatasu/article/view/1056

Joseph, N. M., Hailu, M., \& Boston, D. (2017). Black Women's and Girls' Persistence in the P-20 Mathematics Pipeline: Two Decades of Children, Youth, and Adult Education Research. Review of Research in Education, 41(1), 203-227.

Khalifa, M. A., Gooden, M. A., \& Davis, J. E. (2016). Culturally responsive school leadership: A synthesis of the literature. Review of Educational Research, 86, 1272-1311. doi: $10.3102 / 0034654316630383$

Khisty, L. L., \& Chval, K. B. (2002). Pedagogic discourse and equity in mathematics: When teachers' talk matters. Mathematics Education Research Journal, 14(3), 154-168. doi:10.1007/bf03217360

Ladson-Billings, G. (1995). Toward a theory of culturally relevant pedagogy. American Education Research Journal, 32(3), 465-491.

Ladson-Billings, G. (2006). From the achievement gap to the education debt: 
Understanding achievement in U.S. schools. Educational Researcher, 35(7), 312.

Langer-Osuna, J. M. (2016). The social construction of authority among peers and its implications for collaborative mathematics problem solving. Mathematical Thinking And Learning: An International Journal, 18(2), 107-124.

Langer-Osuna, J. M. "Authority, identity, and collaborative mathematics." Journal for Research in Mathematics Education 48.3(2017): 237-247.

Langer-Osuna, J. M., \& Nasir, N. S. (2016). Rehumanizing the "Other": Race, culture, and identity in education research. Review Of Research In Education, 40(1), 723743.

Larnell, G. V. (2016). More than just skill: Examining mathematics identities, racialized narratives, and remediation among black undergraduates. Journal for Research in Mathematics Education, 47(3), 233-269.

Martin, C., Polly, D., McGee, J., Wang, C., Lambert, R., \& Pugalee, D. (2015).

Exploring the relationship between questioning, enacted mathematical tasks, and mathematical discourse in elementary school mathematics. The Mathematics Educator, 24(2), 3-27. Retrieved from: https://eric-edgov.jpllnet.sfsu.edu/?id=EJ1085090

McCulloch, A. W., Marshall, P. L., DeCuir-Gunby, J. T., \& Caldwell, T. S. (2013). Math autobiographies: a window into teachers' identities as mathematics learners. School Science and Mathematics, 113(8), 380-389.

Mueller, M., Yankelewitz D., Maher, C. (2014). Teachers promoting student mathematical reasoning. Investigations in Mathematics Learning, 7(2), 1-20. National Center for Education Statistics. (2015). National Achievement Level Results.

Nasir, N.S. (2016). Why should mathematics educators care about race and culture? Journal of Urban Mathematics Education, 9(1), 7-18.

Nasir, N.S. (2002). Identity, goals, and learning: Mathematics in cultural practice. Mathematical Thinking and Learning, 4(2-3), 213-247.

Nasir, N. S., \& Cobb, P. (2002). Diversity, equity, and mathematical learning. 
Mathematical Thinking and Learning, 4(2-3), 91-102. doi: 10.1207/s15327833mt104023_1

Peavey, F. (1997). Strategic questioning: An approach to creating personal and social change. Retrieved from:

http://www.pugetsound.edu/files/resources/strategicquestioningshort.pdf

Pringle, R. M., Brkich, K. M., Adams, T. L., West-Olatunii, C., \& Archer-Banks, D. A. (2012). Factors Influencing Elementary Teachers' Positioning of African American Girls as Science and Mathematics Learners. School Science and Mathematics, 112(4), 217-229

Ramsay-Jordan, N. (2017). Examining the integration and use of culturally responsive mathematics pedagogy in preservice teachers' reflections and practice: Implications for black children. Dissertation, Georgia State University. Retrieved from: http://scholarworks.gsu.edu/mse_diss/45

Reilly, D., Neumann, D. L., \& Andrews, G. (2015). Sex differences in mathematics and science achievement: A meta-analysis of National Assessment of Educational Progress assessments. Journal of Educational Psychology, 107(3), 645-662. doi:10.1037/edu0000012

Reinholz, D., \& Shah, N. (2018). Equity Analytics: A Methodological Approach for Quantifying Participation Patterns in Mathematics Classroom Discourse. Journal for Research in Mathematics Education, 49(2), 140-177.

Rimm-Kaufman, S. E., Baroody, A. E., Larsen, R. A. A., Curby, T. W., \& Abry, T. (2015). To what extent do teacher-student interaction quality and student gender contribute to fifth graders' engagement in mathematics learning? Journal of Educational Psychology, 107(1), 170-185.

Sarason, S. (2004). And what do you mean by learning? Portsmouth, NH: Heinemann.

Steele, C. M. (2011). Whistling Vivaldi: And other clues to how stereotypes affect us. New York: W.W. Norton \& Company.

Steele, C. M. (1997). A Threat in the Air: How Stereotypes Shape Intellectual Identity and Performance. American Psychologist, 52(6), 613-29.

Simpson, A., \& Cole, M. W. (2015). More than words: A literature review of language of mathematics research. Educational Review, 67(3), 369-384. 
The Teaching Channel. (2017).

https://www.teachingchannel.org/video/4th-5th-grade-math-routine

Theoharis, G. (2007). Social justice educational leaders and resistance: Toward a theory of social justice leadership. Educational Administration Quarterly, 43(2), 221258.

Toldson, I. (2019). Why it's wrong to label students 'at-risk.' The Conversation https://theconversation.com/why-its-wrong-to-label-students-at-risk-109621

Wickstrom, M. H. (2015). Challenging a teacher's perceptions of mathematical smartness through reflections on students' thinking. Equity \& Excellence in Education, 48(4), 589-605.

Wilhelm, G. A. (2014). Mathematics teachers' enactment of cognitively demanding tasks: Investigating links to teachers' knowledge and conceptions. Journal for Research in Mathematics Education, 45(5), 636-674. doi:10.5951/jresematheduc.45.5.0636

Willingham, D. T. (2009). Why don't students like school? Because the mind is not designed for thinking. American Educator. 4-13.

Ukpokodu, O. N. (2011). How do I teach mathematics in a culturally responsive way? Identifying empowering teaching practices. Multicultural Education, 19(3), 4756. 